\title{
Peter Shaffer en la cultura española
}

\section{RaQuel MERINO-Álvarez \\ Universidad del País Vasco, $\mathrm{UPV} / \mathrm{EHU}$}

\author{
Olaia Andaluz-Pinedo \\ Universidad del País Vasco, \\ $\mathrm{UPV} / \mathrm{EHU}$
}

Título: Peter Shaffer en la cultura española.

Resumen: Este artículo se centra en la integración de las obras del dramaturgo británico Peter Shaffer en las culturas españolas. Durante el franquismo, ayudaron a introducir temas tabúes en los escenarios, tales como la homosexualidad (Five Finger Exercise / Ejercicio para cinco dedos) o el desnudo integral (Equus). Las sucesivas representaciones, ediciones y adaptaciones cinematográficas de las piezas de Shaffer (en particular Amadeus) han consolidado su presencia en el decurso literario del país hasta nuestros días. Siguiendo la metodología TRACE, se analiza en primer lugar el catálogo de traducciones de los dramas de Shaffer, prestando especial atención al proceso de censura, y posteriormente se estudia el corpus textual disponible, utilizando la herramienta Taligner. De esta forma, se pretende ofrecer una visión de supervivencia en España desde 1959 hasta 2016.

Palabras clave: Peter Shaffer, traducción, teatro español, censura, franquismo.

Fecha de recepción: 7/12/2017.

Fecha de aceptación: 26/12/2017.
Title: Peter Shaffer in the Spanish Culture.

Abstract: This article focuses on the integration of the works of British playwright Peter Shaffer in Spanish culture. During the Franco period, this author's plays helped introduce taboo topics on stage, such as homosexuality (Five Finger Exercise / Ejercicio para cinco dedos) or full-frontal nudity (Equus). The successive performances, publications and film adaptations of Shaffer's plays (Amadeus in particular) have consolidated the playwright's presence in the country's cultural life to this date. Following the TRACE methodology, firstly the catalogue of translations of Shaffer's plays is analysed, paying special attention to the censorship process, and subsequently the available textual corpus is studied, using the tool Taligner. By doing so we try to offer a view of Shaffer's perdurance in Spain, from 1959 to 2016.

Key words: Peter Shaffer, Translation, Spanish Theatre, Censorship, Francoism.

Date of Receipt: 7/12/2017.

Date of Approval: 26/12/2017. 


\section{INTRODUCCIÓN ${ }^{\mathrm{I}}$}

En 2016 se anuncia la muerte del dramaturgo británico Peter Shaffer, y el mismo año el público español puede asistir a una nueva reposición de Equus $^{2}$. Shaffer ha muerto pero su obra sigue viva en nuestra cultura gracias a un proceso de integración que había comenzado casi sesenta años atrás con la traducción de Five Finger Exercise (Ejercicio para cinco dedos) ${ }^{3}$, estrenada en Londres en 1958. En Madrid se presentó en el Teatro Beatriz, en marzo de $1959^{4}$. Peter Shaffer asistió al estreno y, con su figura, ayudó a subrayar lo que para muchos sería un hito: el debut en un teatro comercial de un drama con sutiles connotaciones a un tema tabú, la homosexualidad 5 .

En los años sesenta del siglo pasado las representaciones de Shaffer en coliseos españoles se suceden, coincidiendo con periodos de cambio en la cultura de nuestro país. Así, su obra Equus marca un antes y un después: se trata del primer desnudo integral masculino (y femenino) autorizado por la censura para su exhibición en una sala comercial, poco antes de la muerte de Franco. El efecto de dicho estreno entre el público y la prensa, salvando una distancia de treinta y tres años, recuerda el revuelo generado

1 Grupo TRALIMA/ITZULIK, GIU 16/48, Universidad del País Vasco, UPV/ EHU (http://www.ehu.eus/tralima/ www.ehu.eus/es/web/tralimaitzulik); proyecto IDENTITRA, MINECO, FFI2015-68572-P, G15/P75.

2 http://ferroviaria.net/equus/

3 Peter Shaffer, Five Finger Exercise, London, Samuel French, 1958. Peter Shaffer, Ejercicio para cinco dedos, Madrid, Escelicer, 1961.

4 http://hemeroteca.abc.es/nav/Navigate.exe/hemeroteca/madrid/abc/1959/02/20/054. html

5 Raquel Merino Álvarez, "La homosexualidad censurada: estudio sobre corpus de teatro TRACEti (desde 1960)", en Traducción y censura en España (1939 1985). Estudios sobre corpus TRACE: cine, narrativa, teatro, ed. Raquel Merino Álvarez, Bilbao, UPV/EHU/Universidad de León, 2007, pp. 243-286, https://addi.ehu.es/ handle/10810/10169. En Raquel Merino Álvarez, "Building TRACE (Translations Censored) Theatre Corpus: Some Methodological Questions on Text Selection", en Translation and Cultural Identity: Selected Essays on Translation and Cross-Cultural Communication, coords. Micaela Muñoz Calvo y Carmen Buesa Gómez, Newcastle, Cambridge Scholars Publishing, 2010, pp. 129-154, https://addi.ehu. es/handle/10810/17411 se reproduce en el Apéndice I el cuadro "Homosexuality appears on Spanish stages via censored translations". 
alrededor de la producción en Broadway de Equus, con Daniel Radcliffe en el papel principal. También en Estados Unidos la obra, y su autor, siguen vigentes y suscitando polémica.

Si la producción de Ejercicio para cinco dedos supuso la entrada de Shaffer en Espańa y la de Equus su consolidación, la integración de la obra de este autor británico se verificaría con el estreno de Amadeus en 1982. La huella del dramaturgo británico en nuestro solar se asienta con las representaciones y reposiciones sucesivas, así como mediante la publicación de sus textos traducidos al español o al catalán, e incluso el estreno y circulación de películas basadas en sus obras ${ }^{6}$. De forma provisional valdría establecer el límite temporal de este estudio en 2016, por coincidir tanto con la muerte de Shaffer ${ }^{7}$ como con la reciente producción de Equus ya mencionada. En todo caso, huelga insistir en que el rastro de Shaffer en España, más allá de su introducción durante el siglo XX, es un hecho constatable en el XXI.

\section{Peter Shaffer: un autor integrado en la cultura española}

Shaffer forma parte de una larga nómina de autores extranjeros cuyas obras vertidas al espańol ayudaron a integrar temas considerados polémicos por la censura vigente. Traducciones de obras de Edward Albee, Graham Greene o Tennessee Williams ${ }^{8}$ fueron piezas clave en la renovación de temas como la moral sexual (adulterio, homosexualidad) en los escenarios españoles ${ }^{9}$. A cargo de dichos traslados descuellan los nombres de

6 Ejercicio para cinco dedos, 1963; El ojo público, 1972; Equus, 1978; Amadeus, 1984. http://www.mecd.gob.es/cultura-mecd/areas-cultura/cine/industria-cine/base-datos-peliculas-calificadas.html.

7 https://elpais.com/cultura, 7 de junio de 2016.

8 María Pérez López de Heredia, Traducciones censuradas de teatro norteamericano en la España de Franco (1939-1963), Bilbao, UPV/EHU, 2004.

9 Raquel Merino Álvarez, "A Historical Approach to Spanish Theatre Translations From Censorship Archives", en Iberian Studies on Translation and Interpreting, eds. Isabel García Izquierdo y Esther Monzó, Oxford, Peter Lang, 2012, pp. 123-140. Véase de la misma cultura Raquel Merino Álvarez, "La historia de las traducciones de teatro inglés en España en el siglo XX: perspectiva desde el proyecto TRACE”, en Lengua, traducción, recepción: en honor de Julio César Santoyo, coords. Rosa Ra- 
Alberto Martínez Adell, José Méndez Herrera o dramaturgos como José López Rubio, cuya mediación resultó clave ${ }^{10}$. En tanto que intermediarios y agentes de la introducción de textos foráneos en las tablas peninsulares, productores, directores y actores argumentaban con frecuencia que el éxito de público en el exterior podría ser aval de un éxito en España, al tiempo que hablaban de homologar nuestro teatro con el producido y representado en Londres, París o Nueva York.

Así, en el contexto de los estudios TRACEti ${ }^{11}$, se ha podido catalogar, a partir de la información contenida en los archivos de censura (AGA, Archivo General de la Administración ${ }^{12}$ ), cientos de traducciones que se presentaron para su autorización, en una cantidad en ocasiones similar a las de los dramaturgos españoles. Tanto es así, que menudean las referencias al malestar de nuestros hombres de teatro por el posible trato de favor dispensado a las obras extranjeras por parte de las instancias censoras:

Mejor suerte corren, sobre todo a partir de mediados de los sesenta (debido a la política supuestamente "aperturista" liderada por Manuel Fraga Iribarne como ministro de Información y Turismo), los autores extranjeros; especialmente aquellos cuyo prestigio hace incuestionable, de cara a la imagen pseudo-democrática que se intenta vender al exterior, su presencia en las carteleras españolas ${ }^{13}$.

badán, Marisa Fernández López, Trinidad Guzmán González, León, Universidad, 2010, pp. 357-384; y "Traducciones (censuradas) de teatro inglés en la España de Franco. TRACE: una perspectiva histórica”, TRANS. Revista de Traductología, 13 (2009), pp. 19-31.

10 Raquel Merino Álvarez, "Censura, traducción e integración en el teatro de la época franquista: José López Rubio, hombre de teatro y traductor", Hispanic Research Journal, 17, 4 (2016), pp. 303-321; Raquel Merino Álvarez, "The Censorship of Theatre Translations under Franco: the 1960s”, Perspectives: Studies in Translatology, 23, 3 (2015), pp. 303-321; y Olaia Andaluz Pinedo, Teatro y traducción (inglésespañol). Análisis comparativo de traducciones comerciales. Who's Afraid of Virginia Woolf?, 2015.

11 Raquel Merino Álvarez, “Traducción y censura: investigaciones sobre la cultura traducida inglés-español (1938-1985)", Represura. Revista de Historia Contemporánea española en torno a la represión y la censura aplicadas al libro, 2 (2017), pp. 139-163.

12 http://www.mecd.gob.es/cultura-mecd/areas-cultura/archivos/mc/aga/fondosdocumentales.

13 Berta Muñoz Cáliz, "Censurado por el franquismo", El Cultural (2006). http:// 
El análisis de los catálogos generales de teatro traducido (TRACEti) nos ha permitido aislar casos representativos en cuanto a autor extranjero (Albee $^{14}$, Greene, Miller, Shaffer ${ }^{15}$, Williams) ${ }^{16}$, tema (adulterio, homosexualidad, cuestiones políticas) o traductor (López Rubio) ${ }^{17}$. Shaffer es sin duda un nombre clave, habida cuenta de que la puesta en escena de sus obras sirvió como ariete que ayudó a importar temas prohibidos o más que controvertidos en el panorama español. Como veremos más adelante, la cronología de la introducción, consolidación e integración de su obra en España coincide con un periodo (1959-1982) crucial en la historia de nuestra cultura. Asimismo, la pervivencia hasta hoy de producciones y publicaciones de sus obras son indicadores del profundo enraizamiento que esta ha tenido en nuestra trayectoria.

Conforme al marco metodológico establecido en el entorno $\mathrm{TRACE}^{18}$, procederemos primero a repasar el catálogo de obras de Shaffer traducidas en Espańa; luego analizaremos su paso por la censura y, finalmente, nos centraremos en el corpus textual compilado hasta la fecha, con especial observancia de las modificaciones textuales vinculadas a los expedientes consultados en el AGA.

www.cervantesvirtual.com/nd/ark:/59851/bmcfx948

14 Raquel Merino Álvarez, "Building TRACE (Translations Censored) Theatre Corpus: Some Methodological Questions on Text Selection"; y Olaia Andaluz Pinedo, op. cit.

15 En Raquel Merino Álvarez, "Mapping Translated Theatre in Spain through Censorship Archives", en Global Insights on Theatre Censorship, eds. Catherine O'Leary, Diego Santos y Michael Thompson, Oxford, Routledge, 2016, pp. 176-190; “A Historical Approach to Spanish Theatre Translations From Censorship Archives"; y "Traducciones (censuradas) de teatro inglés en la España de Franco. TRACE: una perspectiva histórica”, donde ya se apuntaba la conveniencia de abordar, desde la perspectiva de la censura, el estudio de las obras de Shaffer traducidas para la escena espańola.

16 María Pérez López de Heredia, op. cit.

17 Raquel Merino Álvarez, "Censura, traducción e integración en el teatro de la época franquista: José López Rubio, hombre de teatro y traductor".

18 Raquel Merino Álvarez, "Traducción y censura: investigaciones sobre cultura traducida inglés-español (1938-1985)"; Raquel Merino Álvarez (ed.), Traducción y censura en España (1939-1985): Estudios sobre corpus TRACE: cine, narrativa, teatro, León, Universidad de León, 2007. Véase asimismo Rosa Rabadán (ed.), Traducción y censura inglés-español: 1939-1985: estudio preliminar, León, Universidad de León, 2000. 
Para el catálogo y el corpus textual seleccionado (en Apéndice), tomaremos como referencia la división en sub-periodos que propone Muñoz Cáliz $^{19}$ respecto al funcionamiento de la censura durante el franquismo. Tras el periodo de autarquía (1939-1945) y el que Muñoz Cáliz rotula como "primeras voces disidentes" (1946-1958), tendríamos uno de desarrollo, enmarcado por los límites de la denominada "apertura" (1959-1968); un ciclo de decadencia y aislamiento crítico (1969-1975), y a partir de 1976 comenzaría la desaparición de la censura, que culmina, desde el punto de vista legislativo, en 1977 y 1978, aunque en lo relativo al archivo burocrático de expedientes de teatro (de ordenación y calificación) se cerraría en 1985 con la profunda reorganización del Ministerio de Cultura.

La entrada, consolidación e integración de la obra de Shaffer en la cultura española se puede pues abordar según la división en periodos antedicha, en concreto a partir de 1959, hasta la desaparición de la censura franquista, que tanto rastro ha dejado en forma de expedientes, textos y documentos de gran valor. El Archivo General de la Administración (AGA) es para los estudiosos de la historia de la traducción al español un rico yacimiento documental, en ocasiones la única fuente de información sobre autores y textos extranjeros que fueron traducidos y representados en nuestro país. Un repaso somero a prácticamente cualquier historia del teatro, como ya se ha apuntado, da fe de los grandes vacíos de información con respecto al componente traducido de nuestra cultura dramática. De ahí que nos hayamos servido de fuentes como el AGA, el Centro de Documentación Teatral, la Biblioteca Nacional, el ISBN y la Red de Bibliotecas Públicas del Estado y de Bibliotecas Universitarias (REBIUN), junto con bases de datos sobre cine del Ministerio de Cultura, compilaciones de críticas aparecidas en la prensa diaria, como la acometida por Francisco Álvaro ${ }^{20}$, para desentrañar cuáles fueron los

19 Berta Muñoz Cáliz, "El teatro silenciado por la dictadura franquista", Per Abbat. Boletín Filológico de Actualización Académica y Didáctica, 3 (2007), pp. 85-96; Expedientes de la censura teatral franquista, Madrid, Fundación Universitaria Española, 2006; y El teatro crítico español durante el franquismo, visto por sus censores, Madrid, Fundación Universitaria Española, 2005.

20 Francisco Álvaro, El espectador y la crítica. El teatro en España en 1975, Valladolid, ed. del autor, 1975; El espectador y la crítica. El teatro en España en 1967, Valladolid, ed. del autor, 1967; El espectador y la crítica. El teatro en España en 1964, Valladolid, ed. del autor, 1964; y El espectador y la crítica. El teatro en España en 1959, Vallado- 
autores y los títulos que se deslizaron por el teatro español para completarlo y conformarlo.

Sin los exhaustivos archivos de censura del AGA no habríamos podido fundamentar este estudio, ni tampoco cotejar textos publicados con libretos allí guardados, para así completar una parcela de la historia del devenir escénico en España y en español (original y traducido). El teatro escrito originalmente en inglés fue, sin duda, la principal fuente de la que bebieron los coliseos españoles. En este sentido, la obra de Peter Shaffer es representativa del colectivo que encabezan, atendiendo a la cantidad de sus obras registradas en el AGA, autores como William Shakespeare, Samuel Beckett, Tennessee Williams, George B. Shaw, Edward Albee, Arthur Miller y Graham Greene ${ }^{21}$.

Del mismo modo, el conjunto de la obra de Shaffer en español resulta significativo a la luz del teatro difundido en el circuito comercial en Madrid o Barcelona, siguiendo la estela de Londres o Nueva York, y por tanto orientado al público mayoritario. Si a todo ello unimos el hecho de que, desde la primera representación (Ejercicio para cinco dedos, 1959), la temática de su teatro y la propia identidad del autor fueron utilizados como revulsivo para poner sobre la mesa temas espinosos, el estudio de las piezas de Shaffer traducidas al español es sin duda representativo de un periodo presidido por la censura, y de un modo de renovar nuestro teatro mediante la traducción de dramas extranjeros.

2.1. Shaffer en España, 1959-1968: Ejercicio para cinco dedos, El oído privado / El ojo público, El apagón

El 20 de febrero de 1959 se publicó en $A B C$ la reseña del estreno de Ejercicio para cinco dedos en Madrid, seis meses después del debut londinense y diez antes que la producción neoyorkina, completando así un proceso iniciado con la solicitud de permiso de representación, presentada por Alberto González Vergel (director) el 9 de enero ante las instancias censoras.

lid, ed. del autor, 1959.

21 Remitimos a Raquel Merino Álvarez, "Mapping Translated Theatre in Spain through Censorship Archives”, pp. 183-184; y Raquel Merino Álvarez, "Traducciones (censuradas) de teatro inglés en la Espańa de Franco. TRACE: una perspectiva histórica”. 
Como veremos más abajo, la tramitación por parte de los organismos encargados de juzgar obras teatrales fue rápida, aunque no exenta de trabas. La autorización de la puesta en escena de esta obra, como en otras ocasiones, venía precedida por el aval del éxito londinense, sí, pero también - y de esto tenemos pocas evidencias documentales_ del polémico halo que destilaban algunos pasajes y de la propia condición del autor, que era conocida, aunque no aireada, y sí compartida en los ambientes teatrales.

Sería arriesgado afirmar que las leves connotaciones a causa de la homosexualidad que afloran en la obra hayan sido la principal causa para la elección del autor y la pieza por parte de productores y empresarios. En todo caso, cuando en 1975 se estrenó Los chicos de la banda, de Mart Crowley, el propio Francisco Álvaro, entre otros críticos, se encargaría de establecer los antecedentes de dramas que se hubieran ocupado ya de tan resbaladizo tema en los escenarios espańoles, y Ejercicio para cinco dedos es un claro referente y antecedente: "El tema no es nuevo en nuestra escena. Se ha tratado en Té y simpatía, en Ejercicio para cinco dedos"22.

Si la presencia de Shaffer en el estreno de su primera obra traducida al español (febrero de 1959) es por sí mismo un dato muy significativo, el homenaje que se le tributó en abril del mismo año supone el refrendo del mundo teatral (empresarios, directores, críticos o dramaturgos), tal y como podemos constatar en la breve nota de prensa (en Apéndice):

22 Francisco Álvaro, El espectador y la crítica. El teatro en España en 1975, pp. 86-90 (p. 86); El espectador y la crítica. El teatro en España en 1959, pp. 98-101. El tema, la homosexualidad, había sido introducido, hasta donde se ha podido rastrear, a través de obras autorizadas principalmente para sesiones únicas en Teatros de Cámara: $L a$ gata sobre el tejado de zinc (expediente 217/50, 228/58, 7/59) y Un tranvía llamado deseo (expediente 300/56) de T. Williams, Té y simpatía (expedientes 358/55, $338 / 56,61 / 57,299 / 62)$ de R. Anderson. Ejercicio para cinco dedos marca un punto de inflexión al eclosionar en el teatro español directamente en una producción comercial. Historia del zoo de E. Albee (expediente 75/63, 118/69) incide en el mismo tema que las anteriores y, desde su autorización para sesiones únicas en teatros minoritarios en 1963, no será estrenada en un teatro comercial hasta 1973. Los chicos de la banda se prohibió en 1970 y 1972, respectivamente (expediente 267/70), y llegaría a las tablas en 1975 (533/74). Véase al respecto Raquel Merino Álvarez, "Building TRACE (Translations Censored) Theatre Corpus: Some Methodological Questions on Text Selection”; Raquel Merino Álvarez (ed.), Traducción y censura en España (1939-1985): Estudios sobre corpus TRACE: cine, narrativa, teatro, p. 145; y María Pérez López de Heredia, op. cit. 
El próximo domingo, día 12, se celebrará en el Infanta Beatriz un homenaje en honor del autor de "Ejercicio para cinco dedos", Peter Shaffer. La representación extraordinaria de dicha obra estará patrocinada por el Instituto Británico. Don Nicolás González Ruiz, en nombre de la Asociación de la Crítica, y D. Antonio Buero Vallejo, por los autores españoles, ofrecerán el agasajo a Shaffer, que asistirá personalmente a la función.

La rápida resolución del expediente 6/59, que desemboca en la autorización para teatros comerciales, ilustra a las claras esta entrada organizada y sancionada de Shaffer en nuestro país. Firma la solicitud González Vergel (director artístico, co-traductor y adaptador); y los tres miembros de la Junta de Censura encargados de leer y valorar la obra (Cano, Villares y Montes Agudo) emiten sus informes: a favor de la prohibición, a la espera de la opinión de instancias eclesiásticas el primero; propicios a la autorización, con ciertos cambios en el texto, los otros dos censores. Entre los comentarios identificados en los informes, podemos leer que estamos ante una obra "vulgar" y "turbia" que trata sobre una familia "amoral y desunida", salpicada de ciertos "excesos verbales". Con todo, la sección ratifica la resolución y emite la primera guía de censura (documento necesario para llevar a cabo la representación), indicando ciertas supresiones que comentaremos más adelante al abordar la comparación textual del corpus. Acompañan al expediente 6/59 el texto mecanografiado de la obra. En sucesivas peticiones, archivadas en el mismo expediente y tramitadas en 1966 (expediente 6/59, guías 2 y 3), se adjunta copia de la edición de la obra ${ }^{23}$.

Estos textos, tanto el mecanografiado como el publicado, han propiciado la construcción de un corpus paralelo digitalizado (ShafferES_ejercicio), que cuenta con más de 74.000 palabras y ofrece una visión del modo en el que este drama se ha trasvasado al español. La compilación del corpus ha implicado tareas de digitalización, limpieza, etiquetado y alineación del texto original en inglés y las dos traducciones disponibles. Para ello, hemos utilizado la herramienta Taligner ${ }^{24}$.

A partir de las tachaduras identificadas en la documentación del expediente 6/59, se han rastreado los fragmentos afectados directamente por

23 Peter Shaffer, Ejercicio para cinco dedos, Madrid, Escelicer, 1961.

$24 \mathrm{http}: / /$ www.ehu.eus/tralima/taligner.html. 
la censura. Aunque en el texto publicado por Escelicer no se observan las marcas del lápiz rojo, todo apunta a que se ordenó eliminar las mismas oraciones que en la traducción autorizada en la guía de censura 1, en la que sí se observan los cortes. Las supresiones, con indicación de número de página, se recogen en las correspondientes guías de censura (1, 2 y 3).

Las expresiones censuradas tienen en común que tratan explícitamente asuntos relacionados con la moral sexual, contraria a la propugnada por el Régimen (en Apéndice):
a) Pero como es viuda no se le puede censurar [por tener amantes], ¿verdad?
b) Ella [Louise, la madre] estaba medio desnuda y él [Walter, el pro- fesor] la estaba besando.
c) ¡Hazme arder en deseo!
d) ¡Qué estupendo sería que les hiciese un niño a todas las chicas de Ipswich!
e) Convirtiese a mi hijo en un marica.

Además, mediante la comparación textual se puede observar que, en la réplica en la que se suprime "Ella estaba medio desnuda y él la estaba besando", el traductor habría omitido la expresión que se pronuncia a renglón seguido en el texto inglés, “On the breasts" ('en los pechos'), quizá un vestigio de autocensura.

Más allá de la comparación de los fragmentos con tachaduras, el análisis global del corpus revela que las dos traducciones, ambas firmadas por Alberto Martínez Adell ${ }^{25}$, son casi idénticas. En general, reflejan el diálogo del original, aunque se omiten algunas palabras y réplicas y se añaden otras. También se observa la combinación de dos réplicas de un mismo personaje o de personajes diferentes en una sola, y algún caso de división de una réplica en dos. Por ejemplo,

- Louise: So you should be. That was very, very ill-bred. (Más te vale. Ha sido de muy, muy mala educación)

25 Se trata de un traductor profesional de autores como Andersen, Conrad o Ibsen (http://www.mcu.es/webISBN). En el mundo del teatro figuran como tales profesionales dedicados a la traducción, pero también dramaturgos, actores o directores que firman versiones y adaptaciones. 
- Clive: [whispering] Not really done? ([en voz baja] ¿No has terminado?)

- Louise: Clive, I don't understand you this morning. I really don't. (Clive, no te entiendo esta mañana, de verdad que no)

se traduce tal que así:

- Luisa: ¡Qué mala educación! No os entiendo esta mañana. De verdad que no os entiendo;

mientras que

- Pamela: [pulling away from him] Clive, tell me a story. ([tirando de él] Clive, cuéntame un cuento)

es vertido al español como:

- Pamela: [De pronto] Clive.

- Clive: ¿Qué?

- Pamela: Cuéntame un cuento.

Respecto a decisiones de traducción recurrentes, las referencias a la realidad del Reino Unido se sustituyen por términos más generales (por ejemplo, "Cambridge University" se traduce por "universidad") y las expresiones en francés de ciertos diálogos generalmente se mantienen en esa lengua. En la supresión de "On the breasts" ('en los pechos'), se podría ver un intento de acomodar los textos a lo aceptado por la censura en la traducción de algunas palabras concretas, como "make love" ('hacer el amor'), parafraseado muy libremente como "insinuarse".

Por otra parte, lo más llamativo es el elevado número de acotaciones que desaparecen y la pérdida de información que ello implica de cara a la representación. También se añade alguna acotación con contenido creado por el traductor. Así pues, las didascalias son la parte del texto que más modificaciones sufre.

En las siguientes réplicas, se observan algunos de los fenómenos ya comentados: la tachadura de un guiño directo a la homosexualidad, "convirtiese a mi hijo en un marica"; la reproducción casi idéntica de palabras en las dos traducciones, excepto por la adición de la acotación "[Pausa]" 
en el texto publicado en Escelicer; y la omisión de las dos acotaciones presentes en el original. La tachadura da lugar a una oración incompleta y hace que la siguiente réplica, una reacción a las palabras suprimidas, pierda sentido.

\begin{tabular}{|c|c|c|}
\hline ejercicio_EN.xml - Longitud 1427 & $\begin{array}{l}\text { ejercicio_ES_libreto mecanografia- } \\
\text { do.xml - Longitud } 1427\end{array}$ & $\begin{array}{l}\text { ejercicio_ES_Escelicer.xml - Longi- } \\
\text { tud } 1427\end{array}$ \\
\hline $\begin{array}{l}\text { 1282\#: WALTER: You forget - } \\
\text { you asked me for my opinion. }\end{array}$ & $\begin{array}{l}\text { 1282\#: WALTER: Se olvida de } \\
\text { que fue usted el que me pregun- } \\
\text { tó mi opinión. }\end{array}$ & $\begin{array}{l}\text { 1282\#: WALTER: Se olvida de } \\
\text { que fue usted el que me pregun- } \\
\text { tó mi opinión. }\end{array}$ \\
\hline $\begin{array}{l}\text { 1283\#: STANLEY: Oh yes. } \\
\text { And what else did I ask you to } \\
\text { do? [He moves to L of Walter] } \\
\text { Turn my son into a cissy? }\end{array}$ & $\begin{array}{l}\text { 1283\#: STANLEY: ¿Y qué más? } \\
\text { ¿Le pedí también que *convier- } \\
\text { tese a mi hijo en un marica?* } \\
\text { [TACH] }\end{array}$ & $\begin{array}{l}\text { 1283\#: STANLEY: ¿Y qué más? } \\
\text { ¿Le pedí también que convierte- } \\
\text { se a mi hijo en un marica? }\end{array}$ \\
\hline 1284\#: & 1284\#: & 1284\#: [Pausa] \\
\hline $\begin{array}{l}\text { 1285\#: WALTER: [retreating } \\
\text { below the armchair] Your son is a } \\
\text { fine, intelligent boy. }\end{array}$ & $\begin{array}{l}\text { 1285\#: WALTER: Su hijo es un } \\
\text { muchacho bueno e inteligente }\end{array}$ & $\begin{array}{l}\text { 1285\#: WALTER: Su hijo es un } \\
\text { muchacho bueno e inteligente }\end{array}$ \\
\hline
\end{tabular}

El 18 de marzo de 1964 se abre el expediente 62/6426, correspondiente a la solicitud de permiso y firmada por González Vergel, en nombre de la compañía de Lina Rosales, para la puesta en escena de El oído privado y El ojo público, con vistas a su representación en el Teatro Club de Madrid. González Vergel figura como traductor (junto con Miguel Rubio), adaptador y director escénico. Se sigue el trámite habitual, y los tres censores (Artola, Mostaza y Arroitia) a los que se envían las obras para su valoración subrayan su carácter cómico y proponen cortes y modificaciones en dos páginas, autorizándose por fin el 25 de marzo. Los fragmentos textuales marcados para su supresión, citados en el dorso de la guía de censura, se refieren al segundo acto, páginas 11 y 50 : "sexualmente [infiel]", "[ser testigo] de una copulación", "[deseo] de copulación".

La valoración de la crítica es favorable, aunque no unánime, y destacan las referencias al primer éxito de Shaffer en nuestros lares: "Son dos

26 Se ha encontrado este expediente en el AGA, archivado junto con el 6/59 comentado más arriba. 
ensayos. $\mathrm{O}$ dos cuentos dramáticamente desarrollados. $\mathrm{O}$ dos ejercicios del autor para hacer dedos" 27 . Sin duda, Shaffer se considera ya un autor conocido; los comentarios en prensa y la forma de tramitar y archivar el expediente 62/64 en el AGA, justo en la carpeta que contiene el de Ejercicio para cinco dedos, son datos dignos de nota.

En 1967 la compañía de Juanjo Menéndez somete a censura la obra $E l$ apagón, en versión de Vicente Balart (expediente 362/67). Una vez más, Shaffer es tratado sin excesiva severidad. Los comentarios recogidos en los informes de los tres censores (Artola, Barceló, Sunyer) sugieren indicar en la resolución de autorización la conveniencia del visado de ensayo general, reflejada en la advertencia al dorso de la guía de censura:

al visar el ensayo general se cuidará muy especialmente la realización de las escenas de la pág. 56 , acto $1^{\circ}$, y de las págs. 1 y 15 del acto $2^{\circ}$, y se evitará, asimismo, que en la interpretación y realización de la obra se produzcan situaciones o insinuaciones equívocas de carácter homosexual.

Se autoriza la representación en teatros comerciales el 8 de diciembre, apenas diez días después del registro de la solicitud. En el informe del censor que asistió a dicho ensayo general y al estreno en el Eslava se recomienda que: "se ordene la supresión de la frase «Vd. haría gran carrera en el ejército»". Dicha recomendación se comunica a los responsables de la empresa y queda registrada en la sección de licencias e inspección y sumada al expediente.

Sin duda, el teatro de Shaffer se sitúa en el centro del periodo de "apertura", cuyos síntomas se perciben ya en 1959. Tuvo su apogeo entre 1963 y 1967, con José María García Escudero al frente de la Dirección General de Cinematografía y Teatro. Se halla la producción de Shaffer en el núcleo del sistema teatral y del circuito comercial, liderando la introducción de tramas que retan las normas no escritas de censura, y aquellas que, a partir

27 http://hemeroteca.abc.es/nav/Navigate.exe/hemeroteca/madrid/abc/1964/03/31/089. html (31 marzo 1964). Véase también Francisco Álvaro, El espectador y la crítica. El teatro en España en 1964, pp. 217-220. 
de 1963, se explicitan mediante publicación en el BOE; las mismas que atañían a la moral sexual, entre otras limitaciones. Ejercicio para cinco dedos supone un triunfo hacia la apertura a temas y situaciones controvertidas al comienzo del periodo que hemos examinado en esta sección, y El oído privado y El ojo público, pero sobre todo El apagón, continúan la estela de ese primer éxito de público, en el tramo final de una etapa que acabaría con el cese de los responsables al frente de la Dirección General de Cinematografía y Teatro (1967) y del Ministerio de Información y Turismo (1969). Si los autores extranjeros parecían tener más opciones de ser el vehículo del cambio, al objeto de retar el control vigente en los escenarios, algunos, como Shaffer, parecen haber sido respaldados por agentes del propio sistema teatral espańol, además de ver refrendado su éxito por la taquilla.

\subsection{Shaffer en España, 1969-1975: La caza real del sol, Equus ${ }^{28}$}

La travesía benévola de Shaffer en el círculo teatral español se ve interrumpida en 1969. La solicitud de permiso para representar La caza real del sol choca con escollos, al parecer insalvables, que llevan a su prohibición. En el dilatado expediente consultado en el AGA (3/69), que incluye el texto traducido, se puede verificar que se ha impuesto una involución en el aparato censor, en su intento de frenar el torrente de cambio desatado durante los ańos de "apertura". Una vez alejados de los puestos de poder los anteriores responsables políticos, se imponen posturas restrictivas que pretenden contener o revertir el orden recién iniciado. Si a esta nueva situación en las instancias oficiales unimos el tema de la obra, la conquista de Perú, se sirve en bandeja la oposición al uso indebido del "buen nombre de España". El escrutinio de los censores no ve con buenos ojos que un autor inglés dé pábulo a la "leyenda negra", poniendo en tela de juicio un episodio "intocable" de la historia patria.

La solicitud de permiso de representación se tramita, y se envía el texto a tres censores que emiten sus respectivos informes: dos recomiendan la prohibición y uno se decanta por la autorización. Entre las objeciones que se aducen en estos informes, bastará citar las siguientes: "de toda ella

28 Barbara Aszyk, "El teatro español durante la transición política", Sociocriticism, XXXI, 2 (2016), pp. 7-41. 
[la obra] se desprende un cierto tufillo de leyenda negra que tanto se ha utilizado para difamarnos fuera"; o "se nos cuenta, como al descuido, la delicia de la civilización incaica, verdadero anticipo del comunismo ideal. [...] De todas formas me parece advertir en la expresión los paliativos oficios del adaptador, pues si mal no recuerdo, la obra fue comentada con escándalo por algún corresponsal nuestro en el extranjero cuando se estrenó en Inglaterra. [...] La obra debe prohibirse, por lo que supone de apedreo de nuestro propio tejado (Norma 14, 3a)".

El primer informe que se decanta por la autorización habla de "una bella y poética revisión de la prisión y muerte de Atahualpa, sin la menor ofensa a la gesta hispana”. Dada la discrepancia entre censores, se procede a someter la obra a "dos lecturas" adicionales, traducidas en un informe de prohibición y otro de autorización. El expediente pasa a Pleno, lo que supone que cada miembro de la Junta de Censura Teatral emite un informe y dictamen. El resultado se cifra en ocho informes que aconsejan la autorización y nueve la prohibición, más cinco miembros que se decantan, en la sesión final, por la prohibición (en Apéndice).

Las razones esgrimidas en los distintos informes de prohibición se apoyan en la aplicación de la norma 14-3a sobre "falseamiento tendencioso de los hechos, personajes y ambientes históricos", o suscriben comentarios del tipo "ya está bien de leyenda negra"; cuando no apuntan que el mayor problema estriba en la puesta en escena, aunque se efectúen cortes en el texto. En este sentido, el secretario de la Junta de Censura concluye en su informe:

quizá algunos cortes o adaptaciones hicieran viable su representación, pero dadas las características de la pieza, su autor y el conocimiento que de la misma existe en el extranjero, [...] no se aconsejan rectificaciones en el texto, ya que afectarían a la esencia de la obra.

Entre los documentos recogidos en el expediente destaca una carta del traductor-adaptador, Vicente Balart (14 de mayo), solicitando que se le informe del dictamen y, si fuera prohibitivo, se le indique la motivación del mismo. En la respuesta se le aconseja que consulte las Normas publicadas en el BOE $1963^{29}$.

29 Se trata de la carta registrada el 25 de mayo. Firmada por el secretario de la Junta, 
Este expediente constituye una rica fuente de documentación, entre la cual encontramos una nota informativa (14/1/1969), procedente del expediente tramitado por la Junta de Censura Cinematográfica y dirigida al Ilmo. Sr. Director General (Subdirección de Espectáculos), a propósito de la solicitud de permiso de rodaje de La maravillosa conquista del sol, adaptación de la obra The Royal Hunt of the Sun. Se describen a su vez los diversos intentos de rodar la película, la mayoría de ellos en España. Se menciona una primera autorización del guion, el 8 febrero de 1967, y otra del 1 de marzo de 1968, relativa a una petición norteamericana de rodaje en nuestro país de este filme, cuyo guion se autoriza. Se otorgó el permiso el 2 de mayo del mismo año (con dos recomendaciones relativas al tratamiento digno de la figura de los espańoles). El coste de esta producción ascendía, según la nota, a cuatro millones de dólares "importados" de EE.UU. Se indica de forma "oficiosa” que la película se ha rodado en su mayoría en Espańa y que será distribuida en Europa y el resto del mundo.

El 2 de mayo de 1974, el empresario Manuel Collado presenta la segunda solicitud de representación de La caza real del sol para el Teatro Beatriz de Madrid, con dirección de Adolfo Marsillach. La documentación se adjunta al expediente 3/69 y, en apenas doce días, se informa al peticionario de la autorización sin cortes, para mayores de 18 años, amén de expedirse la primera guía de censura correspondiente al expediente 3/69, cinco años después de la prohibición de la obra.

En la instrucción del expediente de 1974, uno de los tres censores a cargo de los informes apunta: "aunque dice el recurrente que se trata de una versión modificada, cuesta trabajo pensar sobre qué razones pudo basarse la anterior prohibición. Tal vez por un patriotismo mal digerido o un sentido religioso, también indigestado".

A pesar de que la autorización y guía de censura son informadas favorablemente, la producción no se llevó a término, quedando esta vez España al margen del circuito de escenarios internacionales en los que subió a las tablas $^{30}$. El estudio de esta 'no-producción' de la obra de Shaffer excede

en ella se cita el BOE del 8 de marzo de 1963.

30 El hombre de la Mancha, de Dale Wasserman (expediente 231/66), musical centrado en los personajes de Cervantes y Don Quijote, es un caso en que el "buen nombre de España” fue defendido en las instancias oficiales, proponiendo cortes y 
los límites de nuestro artículo, aunque sin duda merecería un tratamiento en profundidad.

El expediente relativo a $L a$ caza real del sol se antoja un magnífico exponente de las visiones encontradas de los miembros de la Junta de Censura y ejemplifica de manera prototípica la complejidad del procedimiento, que desemboca en la prohibición de su representación en 1969. Asimismo, ilustra las tensiones que surgieron en un momento de cambio e involución en el seno del Ministerio de Información y Turismo. En cuanto a la función del libreto teatral en el proceso de lectura y censura, es importante consultar las indicaciones de cortes y adaptaciones, pero también los cambios que ya habrían sido integrados por el traductor y adaptador. Dado que se trata de una obra que no ha sido representada ni publicada en España, el material textual relacionado con el expediente 3/69 es, en sí mismo, un hallazgo digno de análisis.

La traducción suscrita por Vicente Balart, cuyo libreto mecanografiado forma parte del expediente 3/69 archivado en el AGA junto con la obra original inglesa ${ }^{31}$, constituye el corpus paralelo ShafferES_caza, de más de 42.100 palabras. El análisis del texto presentado a la censura, que aparece bajo el nombre de "versión", revela varios cambios respecto al original. Entre ellos, destaca por razones cuantitativas la supresión de réplicas y la combinación del contenido de dos o tres réplicas en una. Además, hay varios casos de omisión y de adición de palabras en los diálogos de los personajes. También se añaden réplicas, aunque en menor medida. Otra cuestión sorprendente es que, en determinados casos, se atribuyen diálogos de unos personajes a otros y se modifican las cantidades expresadas por algunos números.

Las acotaciones también sufrieron omisiones y añadidos. Sin embargo, quizá uno de los aspectos de mayor interés es la reformulación o la eliminación de fragmentos en los que se critica a España o la religión. Se puede tomar a modo de ejemplo la réplica "I have settled several lands. This is the first I've entered which shames our Spain" ('He visitado muchos paí-

cambios, pero avalando la producción en un intento por hacer ver que la "apertura" era ya un hecho en 1966. Véase Raquel Merino Álvarez, "Censura, traducción e integración en el teatro de la época franquista: José López Rubio, hombre de teatro y traductor".

31 Peter Shaffer, The Royal Hunt of the Sun, Harmondsworth, Penguin, 1981. 
ses y este es el primero que deja en evidencia a España'), que se traduce como "Por mi vida que he pisado muchos países y éste es el primero en que hallo un entendimiento cabal de lo que debe ser el gobierno de una nación..."; o bien la frase dirigida a Atahualpa "They want to write psalms to their god in your blood" ('Quieren escribir salmos a su dios con tu sangre’), objeto de supresión. A pesar de estos posibles intentos de autocensura, como se ha expuesto, los censores se opusieron a la difusión de esta mirada sobre la conquista de Perú.

En la siguiente imagen del corpus ShafferES_caza se observa un ejemplo de las modificaciones del diálogo que sufre la traducción. En la primera réplica, se ańade la primera oración y se reformulan las palabras del texto original a fin de evitar la pulla directa a la Iglesia: "So there is Christian charity. To save my own soul I must kill another man" ('Ahí tienes la caridad cristiana: para salvar mi alma debo matar a otro hombre') se traslada como "Me agobia esa voz que para salvar mi propia alma, me pide que mate a un semejante". A continuación, se elimina la réplica de De Nizza, se omite la primera oración de la réplica de Pizarro, "Hail to you, sole judge of love! No salvation outside your church: and no love neither! Oh, your arrogance! ...” (“Te saludo, único juez del amor! ¡No hay salvación fuera de tu Iglesia, y tampoco amor! ¡Qué arrogancia!'), se añaden palabras a la acotación y se une el resto del contenido a la réplica anterior.

1209\#: PIZARRO: So there is Christian charity. To save my own soul I must kill another man!
1209\#: PIZARRO: No soy más que un pobre aldeano sin ilustración, pero pienso que muchas cosas deberían ser distintas en este mundo nuestro. Me agobia esa voz que para salvar mi propia alma, me pide que mate a un semejante. [Profundo $y$ sencillo] No conozco el amor, padre, pero ¿cómo podré conocerlo alguna vez si no siento amor por el Inca?

1210\#. [DE NIZZA: To save love in the world you 1210\#: must kill lovelessness.]

1211\#: PIZARRO: Hail to you, sole judge of 1211\#: love! No salvation outside your church and no love neither! Oh, you arrogance!... [Simply] I do not know love, Father, but what can I ever know, if I feel none for him? 
El expediente de La caza real del sol, tal y como se ha visto, tras un complejo proceso censor, culmina en sendos dictámenes de prohibición (1969) y autorización (1974), y desemboca en la no-producción de esta obra, de la que, por tanto, se privó al público español. Luego el estudio de la misma queda limitado al análisis de la abundante documentación sobre el proceso censor. En el caso de Equus ocurre justo lo contrario, ya que no se ha podido localizar en el AGA la documentación del expediente inicial (324/74) que dio lugar al estreno en octubre de 1975, aunque sí contamos con copias del libreto traducido (AGA cajas 85564 y 85556). Se ha podido acceder a un segundo expediente (237/83), correspondiente al periodo en el que se seguían tramitando expedientes de "ordenación" por parte de la sección correspondiente del Ministerio de Cultura.

Aunque no hayamos accedido a la documentación del expediente 324/74, se ha recopilado información de diversas fuentes (prensa, publicación de la obra) que nos permiten constatar que Equus corrió mejor suerte a su paso por la censura. Tras un proceso que suponemos largo y complejo, la obra de Shaffer se estrena en Espańa semanas antes de la muerte de Franco, y supone un hito, toda vez que en la representación aparecen los primeros desnudos (masculinos y femeninos) autorizados para un teatro comercial ${ }^{32}$. Una vez más, la traducción de un texto extranjero consiguió lo que parecía vedado a los españoles. Se rompe un nuevo tabú, el del desnudo. Y coincide Equus, en la cartelera madrileña, con otras dos obras polémicas, una en torno a la homosexualidad y la otra una visión para algunos "irreverente" de la figura de Cristo: Los chicos de la banda y Jesucristo Superstar.

De la reacción de la crítica, según las notas y artículos de prensa reproducidos en el volumen editado por Francisco Álvaro en 1975 y luego en la edición de $A_{y m a ̀}{ }^{33}$, lo primero que llama la atención es la visualiza-

32 Es probable que el proceso de censura que llevó a la autorización de Equus fuera tan complejo como el de Los chicos de la banda, una obra de Mart Crowley en la que se representa la fiesta que celebran un grupo de homosexuales. El expediente de la obra de Crowley se inició en 1970 y desembocaría en un estreno de gran repercusión mediática (1975). Véase Raquel Merino Álvarez, "La homosexualidad censurada: estudio sobre corpus de teatro TRACEti (desde 1960)".

33 En la edición española de Aymà (Peter Shaffer, Equus, Barcelona, Aymà, 1979), se 
ción de una de las situaciones polémicas: el desnudo de los protagonistas. Para la portada de la edición española se eligió una fotografía del estreno londinense, en la que aparece el actor vestido, mientras que el volumen editado por Francisco Álvaro en 1975 viene porticado por una fotografía en la que el actor principal figura desnudo (en Apéndice).

De hecho, el desnudo es objeto de comentario por parte de los críticos, que afirman que "existía gran expectación ante el estreno", tanto por la obra como por el autor, "pero también por cierta situación de esta pieza que obliga — o así se decía — a mostrar en escena el desnudo total de dos de sus intérpretes". Se dice que "el desnudo o los desnudos previstos quedaron reducidos a dos cuerpos [...] hipócritamente cubiertos, con sendos 'slips". En la misma recopilación de críticas se apunta que el estreno se demoró por "dificultades surgidas entre la Administración y el director y promotor de la obra", lo que "redobló la 'curiosidad' del público expectante". En Álvaro leemos que

ya avanzadas las representaciones, con llenos diarios absolutos, grupúsculos de ultras, fanáticos de la "moralidad" a ultranza, lanzaron amenazas verbales y escritas contra la actriz intérprete del desnudo en cuestión, porque todavía les parecía pecaminoso. Y hete aquí que esto y la originalidad que para nuestros espectadores suponía el montaje y configuración del espectáculo [...] resulta el mejor aliciente, la mejor propaganda para el éxito, que continúa en Madrid y se prolongará en provincias.

Se subraya que "lo del desnudo integral" no era "ni mucho menos imprescindible a la verificación de la obra, ni, por supuesto, necesario", pero "ello ha contribuido considerablemente al éxito", alimentado por la polémica planteada y por la curiosidad del público por ver "en qué había quedado todo. [...] Había en el ambiente una inquietud malsana por saber si por fin se había autorizado o no el desnudo integral en una escena muy cruda”.

incluye una "Nota del autor" en la que Peter Shaffer se refiere a la producción de 1973 en el National Theatre de Londres, y, como colofón, una sección, "Equus y la prensa” (pp. 143-145), en la que se reproducen algunas de las críticas aparecidas con motivo de su estreno en España. 
En la crítica que firmó Martí Farreras, con motivo del estreno de Equus en Barcelona, reza que "podemos comprobar en esta curiosísima pieza" que su autor "sigue trabajando con tenacidad sobre zonas patéticamente vidriosas, a lo que sin duda no es extrańa la propia condición del autor, como ser marginado en la misma sociedad en la que vive" ${ }^{34}$.

Tal y como observa Barbara Aszyk,

el público burgués madrileño no se escandalizó, al contrario; la obra se mantuvo en el escenario durante tres temporadas. José Monleón, crítico teatral de la oposición antifranquista y fundador de la revista Primer Acto, lo comenta con entusiasmo: puesta en escena un mes antes de la muerte de Franco, la pieza "marca el comienzo de una nueva etapa" en el teatro, ya que el desnudo, anteriormente prohibido, "hizo del drama de Shaffer [...] uno de los grandes éxitos de taquilla, en Madrid y en cuantas ciudades españolas se presentó" (Monleón, 1978, 77) ${ }^{35}$.

Equus fue un éxito en Espańa, de igual modo que lo había sido antes en Londres o Nueva York; mas dicho triunfo, y hasta el estreno en sí, quizá no hubieran sido posibles sin la percepción de que Shaffer era ya un autor más, y asiduo, en la escena española: lo que se dice un "marginado". Su producción se había integrado en nuestro país, fundiéndose con el producido por dramaturgos españoles, con reposiciones y publicaciones.

Como ya se ha apuntado, la documentación hallada en el AGA a propósito de Equus se reduce a un expediente de 1983 (237/83) y al libreto relativo a la solicitud de 1974 (324/74). El libreto de Equus, presentado a censura y consultado en el AGA, forma parte, junto con la traducción publicada en Aymà y el original en inglés, del corpus paralelo ShafferES_ equus, que cuenta con más de 72500 palabras. Aunque no ha sido posible observar si se indicaron cortes en los informes censores, el corpus ofrece una visión de la forma en la que las traducciones han dado a conocer la obra en español.

34 Ibidem, pp. 143-145.

35 Barbara Aszyk, "El teatro español durante la transición política”, Sociocriticism, XXXI, 2 (2016), pp. 7-41 (pp. 22-23). 
La comparación textual pone de manifiesto diferencias entre las dos traducciones. Por un lado, la publicada en Aymà sigue muy de cerca el original, salvo en algún caso puntual. Además de la gran similitud entre la expresión en inglés y en español, destaca la división del texto en escenas. Por otro lado, la traducción del libreto introduce numerosas modificaciones respecto al texto de Shaffer, principalmente a través de la supresión de réplicas y la combinación de dos o más de ellas en solo una. Además, se utiliza la versión española del nombre de uno de los personajes, "Esther", y se producen varias omisiones y algunas adiciones de palabras o frases en los diálogos de los personajes. Cabe plantearse si la omisión de alguna de esas voces, como "bottoms" ('culos'), se debe a un intento de limitar el lenguaje soez con vistas al filtro censor. En los diálogos también se observan traducciones de ciertas palabras que cambian su significado sin razón aparente, como la traducción de "madam" (señora) por "señor". Asimismo, se prescinde de algunas acotaciones, aunque este nivel de lengua no sufre tantos cambios como el diálogo. En suma, las dos traducciones difieren en gran medida respecto a la forma de realizar el trasvase. No obstante, en ambas asoma una adición de cuatro réplicas que no están presentes en el texto inglés, lo que nos lleva a pensar que es posible que se consultara la traducción previa.

A continuación, recogemos una muestra del corpus ShafferES_equus en la que se da cuenta de las diferencias más recurrentes. El fragmento del texto impreso en Aymà respeta la distribución de las réplicas y sigue a pies juntillas el diálogo original. También asume la división de la obra en escenas. Por su parte, el texto mecanografiado une el contenido de dos réplicas (la primera y quinta) en una y suprime varias réplicas (la segunda, tercera y cuarta). Asimismo, la traducción de la oración "Ask him about taking a girl out, that very night he did it..." ('Pregúntele si salió con una chica la misma noche en la que hizo eso...') resulta más libre. 


\begin{tabular}{|c|c|c|}
\hline equus_EN.xml - Longitud 1569 & $\begin{array}{l}\text { equus_ES_Aymá.xml - Longitud: } \\
1569\end{array}$ & $\begin{array}{l}\text { equus_ES_libreto mecanografiado. } \\
\text { xml - Longitud: } 1569\end{array}$ \\
\hline $\begin{array}{l}\text { 674\#: FRANK: I cant't say any } \\
\text { more. }\end{array}$ & $\begin{array}{l}\text { 674\#: FRANK: No puedo decir- } \\
\text { le nada más. }\end{array}$ & $\begin{array}{l}\text { 674\#: FRANK: No Puedo decir- } \\
\text { te más. Pregúntele. Pregúntele a } \\
\text { él sobre si sale con alguna chi- } \\
\text { ca... Si salía con alguna aquella } \\
\text { noche... [bruscamente]Adiós, } \\
\text { doctor [Sale. Dysart se le queda } \\
\text { mirando. Frank vuelve a su asien- } \\
\text { to] }\end{array}$ \\
\hline $\begin{array}{l}\text { 675\#: DYSART: I don't quite } \\
\text { understand }\end{array}$ & $\begin{array}{l}\text { 675\#: DYSART: No logro en- } \\
\text { tenderlo. }\end{array}$ & 675\#: \\
\hline $\begin{array}{l}\text { 676\#: FRANK: Everything said } \\
\text { in here is confidential, you said. }\end{array}$ & $\begin{array}{l}\text { 676\#: FRANK: Según usted, } \\
\text { todo cuanto aquí se dice es con- } \\
\text { fidencial. }\end{array}$ & 676\#: \\
\hline 677\#: DYSART: Absolutely. & $\begin{array}{l}\text { 677\#: DYSART: Absolutamen- } \\
\text { te. }\end{array}$ & 677\#: \\
\hline $\begin{array}{l}\text { 678\#: FRANK: Then ask him. } \\
\text { Ask him about taking a girl } \\
\text { out, that very night he did it... } \\
\text { [Abruptly.] Goodbye, Doctor. } \\
\text { [He goes. DYSART looks after } \\
\text { him. FRANK resumes his seat.] }\end{array}$ & $\begin{array}{l}\text { 678\#: FRANK: Entonces, pre- } \\
\text { gúnteselo a él. Pregúntale si salió } \\
\text { con una chica la noche en que lo } \\
\text { hizo... [Súbitamente] Adiós, doc- } \\
\text { tor, [se va] [Dysart mira a Frank } \\
\text { mientras éste vuelve a su asiento.] }\end{array}$ & 678\#: \\
\hline 679\#: & 679\#: ESCENA XV & 679\#: \\
\hline $\begin{array}{l}\text { 680\#: [ALAN gets up and enters } \\
\text { the square.] }\end{array}$ & $\begin{array}{l}\text { 680\#: [ALAN se levanta y entra } \\
\text { en el cuadrilátero.] }\end{array}$ & $\begin{array}{l}\text { 680\#: [ALAN se pone en pie y en- } \\
\text { tra en el cuadrilátero.] }\end{array}$ \\
\hline
\end{tabular}

\subsection{Shaffer en España, 1975-1982: Amadeus}

De la obra Amadeus $^{36}$ no hemos localizado el expediente de ordenación que hubo de mediar antes de su estreno en España, en enero de 1982 ${ }^{37}$,

36 Peter Shaffer, Amadeus, Harmondsworth, Penguin, 1981. La obra se estrenó en el National Theatre de Londres el 2 de noviembre de 1979.

37 El catálogo general TRACEti (http://www.ehu.eus/tralima/catrace.php) recoge el resultado de búsquedas en el AGA que han dado como resultado la localización de expedientes archivados desde 1938 hasta 1985. Tras la promulgación de las leyes sobre libertad de expresión en el teatro, y de la ratificación de la Constitución, el aparato burocrático continuó gestionando las peticiones de "ordenación" y "calificación” hasta mayo de 1985, fecha en la que tuvo lugar la reorganización del Ministerio de Cultura. Así, entre este tipo de expedientes de ordenación, hemos localizado 
aunque contamos con la publicación del texto en la editorial MK ediciones ${ }^{38}$.

La película homónima de Milos Forman se estrenó en España con la misma celeridad con la que se había procedido en el caso de otras adaptaciones cinematográficas de piezas de Shaffer (en Apéndice). En este caso, el propio dramaturgo quiso que la adaptación a la pantalla grande fuera la última de sus posibles reescrituras: en la postdata final a la edición inglesa de la pieza teatral, señala taxativamente que no dejará que Amadeus se convierta en una ópera (como La caza real del sol) o en un ballet (como Equus) ${ }^{39}$.

Lo que Shaffer no quiso (o pudo) impedir es que se sucedieran las reposiciones de sus obras traducidas. Así, Amadeus ha sido un éxito de público continuado en el tiempo, con representaciones que inauguran el siglo XXI en la cartelera teatral española ${ }^{40}$. Del mismo modo se han sucedido reposiciones y nuevas producciones de El apagón ${ }^{41}$ o Equus ${ }^{42}$.

\section{Conclusiones}

Para el gran público internacional, el nombre de Peter Shaffer está indisolublemente unido al de la película Amadeus, dirigida por Milos Forman, y centrada en las figuras de Mozart y Salieri. No son ajenos a este éxito y repercusión mundial el medio cinematográfico y los premios obtenidos, en particular los óscar que otorga la academia de Hollywood. Pero Amadeus no es solo el capolavoro salido de la pluma del dramaturgo británico,

uno correspondiente a Equus (237/83), y es de suponer que se habría archivado el de Amadeus.

38 Peter Shaffer, Amadeus, Madrid, MK Ediciones y Publicaciones, 1982.

39 Peter Shaffer, Equus, Harmondsworth, Penguin, 1984.

40 Anita Viola, Cartelera teatral en ABC de Madrid (2000-2004), Universidad Nacional de Educación a Distancia, 2012.

41 Anita Viola, ibídem, afirma que, en temporadas como la de 1996-1997, fueron las obras de autores extranjeros las que tuvieron mayor aceptación, entre otras El apagón de Shaffer.

42 En la búsqueda realizada en el Centro de Documentación Teatral (30 octubre 2017) se han identificado unos cincuenta documentos referidos a obras de Shaffer representadas en España. http://teatro.es/estrenos-teatro. 
también implica un eslabón más que marca la presencia de Shaffer en el teatro de nuestro país. Tirando de esa cadena imaginaria, y desde una perspectiva histórica, hemos intentado ir más allá, y más atrás en el tiempo, en un intento por reflejar cómo se ha producido la integración de sus obras en la escena patria.

Así, el estudio de las traducciones, vistas como textos asimilados por el decurso dramático de la piel de toro, desde una atalaya historiográfica, avalada por evidencias documentales y textuales, nos permitió celebrar, en 2016, los cincuenta y siete años de Shaffer en España. Las producciones y reposiciones en los principales escenarios, en el circuito amateur y en provincias, los éxitos de taquilla, junto con las ocasiones en que ciertas piezas no salieron a escena, influyeron en la percepción y recepción peninsular de la trayectoria del autor de Equus.

Hay un Shaffer espańol y en español, entretejido en las páginas aún no escritas, o no integradas, en las historias del teatro espańol. Sus textos traducidos al castellano están vivos, y aún vigentes, no solo en las ediciones disponibles sino en esos textos que viajan por todo el país en versiones nuevas y renovadas, celebrando la vitalidad de un dramaturgo importante, importado y, a la postre, integrado en la escena hispánica. 


\section{ApÉNDICE}

\section{Catálogo ShafferES i 959-I 982}

\begin{tabular}{|c|c|c|c|c|c|}
\hline AÑo & Título & Censura & Producción Teatral & Publicación & Cine \\
\hline 1959 & $\begin{array}{l}\text { Ejercicio para } \\
\text { cinco dedos }\end{array}$ & $\begin{array}{l}\text { 6/59 } \\
\text { Guía1 } \\
\text { 6/59 } \\
\text { Guía2 } \\
\text { Guía3 }\end{array}$ & $\begin{array}{l}\text { 20/2/1959 } \\
13 / 4 / 1959 \\
\text { (Función Homenaje a } \\
\text { Peter Shaffer) } \\
\text { T. Beatriz }\end{array}$ & $\begin{array}{l}1961 \text { ES } \\
\text { Alfil-Escelicer, Colección } \\
\text { Teatro } \\
\text { (traductor: Martínez Adell) } \\
{[1958 \text { EN] }}\end{array}$ & $\begin{array}{l}1963 \mathrm{ES} \\
{[1962 \mathrm{EN}]}\end{array}$ \\
\hline $\begin{array}{l}1964 \\
1970\end{array}$ & $\begin{array}{l}\text { El oído privado } \\
\text { El ojo público }\end{array}$ & $\begin{array}{l}62 / 64 \\
450 / 70 \\
451 / 70\end{array}$ & $\begin{array}{l}\text { 1/4/1964 } \\
\text { T. Club } \\
\text { Gira por América } \\
1970\end{array}$ & [1962 EN] & $\begin{array}{l}1972 \mathrm{ES} \\
\text { Sígueme } \\
\text { (Follow me) } \\
{[1971 \mathrm{EN}]}\end{array}$ \\
\hline $\begin{array}{l}1967 \\
1968 \\
1971 \\
2011\end{array}$ & El apagón & $362 / 67$ & $\begin{array}{l}1968 \text { T. Eslava } \\
1971 \text { T. Club } \\
1990 \\
1997 \text { T, Victoria }\end{array}$ & [1965 EN] & \\
\hline $\begin{array}{l}1969 \\
1974\end{array}$ & $\begin{array}{l}\text { La caceria real } \\
\text { del sol }\end{array}$ & $\begin{array}{l}3 / 69 \mathrm{P} \\
3 / 69 \mathrm{~A} \\
1974\end{array}$ & $\begin{array}{l}1974 \text { (no-prod.) } \\
\text { [A. Marsillach, dir.] }\end{array}$ & {$[1964 \mathrm{EN}]$} & \\
\hline 1975 & Equus & $\begin{array}{l}324 / 74^{*} \\
237 / 83\end{array}$ & $\begin{array}{l}\text { 15/10/1975 } \\
\text { T. de la Comedia } \\
1983\end{array}$ & $\begin{array}{l}1974 \text { ES } \\
\text { [1973 EN] } \\
\text { Aymá (traductor: Jordi } \\
\text { Arbonès) }\end{array}$ & $\begin{array}{l}1978 \mathrm{ES} \\
{[1977 \mathrm{EN}]}\end{array}$ \\
\hline 2016 & & & 2016 C. Ferroviaría & $\begin{array}{l}1994 \text { CAT } \\
\text { Edicions } 62 \\
\text { (traductor: Jordi Arbonès) }\end{array}$ & \\
\hline \multirow[t]{2}{*}{1982} & \multirow[t]{2}{*}{ Amadeus } & & $\begin{array}{l}1982 \text { (27 enero) } \\
\text { T. Marquina }\end{array}$ & $\begin{array}{l}\text { 1982ES } \\
\text { [1980EN] } \\
\text { MK (traductora Pilar Salsó) }\end{array}$ & \multirow[t]{2}{*}{$\begin{array}{l}1985 \mathrm{ES} \\
{[1984 \mathrm{EN}]}\end{array}$} \\
\hline & & & & $\begin{array}{l}1986 \text { CAT } \\
\text { Edicions } 62 \text { (trad. Dolors } \\
\text { Vilarasau) }\end{array}$ & \\
\hline
\end{tabular}




\section{ShafferES I959-I982: EXPEDIENTES DE CENSURA CONSUltados EN AGA}

\begin{tabular}{|c|c|c|c|c|c|}
\hline $\begin{array}{l}\text { EXPED. } \mathrm{N}^{\mathrm{O}} \\
\text { Títulu }\end{array}$ & $\begin{array}{l}\text { Cronología } \\
\text { Solicitud } \\
\text { Guía(s) }\end{array}$ & $\begin{array}{l}\text { Peticionario } \\
\text { DireCtor } \\
\text { Traductor } \\
\text { CoMPañía }\end{array}$ & Resolución & $\begin{array}{c}\text { CEnsores } \\
\text { Comentarios }\end{array}$ & $\begin{array}{l}\text { TEXTO: MARCAS/ } \\
\text { CORTES PP. }\end{array}$ \\
\hline $\begin{array}{l}6 / 59 \\
\text { Ejercicio } \\
\text { para cinco } \\
\text { dedos }\end{array}$ & $\begin{array}{l}\text { Solicitud 9/1/59 } \\
\text { "éxito Londres" } \\
\text { Guía1 } \\
\text { Guía } 2 \\
\text { 3/2/66 (M) } \\
\text { 12/2/66(B) } \\
\text { Guía } 3\end{array}$ & $\begin{array}{l}\text { González Vergel } \\
\text { Martínez Adell/González } \\
\text { Vergel } \\
\text { Compañía Andrés } \\
\text { Mejuto } \\
\text { Teatro Beatriz } \\
\\
\text { G2 Agrupación Orfeo } \\
\text { Canigó Cooperativa La } \\
\text { popular sansense } 7 / 2 / 66 \\
\text { (1 día) } \\
\text { G3 (SS) } 1 \text { día } \\
\text { 6/5/66>10/5/66 } \\
\text { Agrupación Antígona } \\
\text { Club vasco camping } \\
\text { (libreto Escelicer, 78782) }\end{array}$ & $\begin{array}{l}\text { G2 3/2/1966 } \\
\text { Grupo Orfeón } \\
\text { (Barcelona) } \\
\text { G3 9/5/1966 } \\
\text { Grupo Antígona } \\
\text { (S. Sebastián) }\end{array}$ & $\begin{array}{l}\text { Valor teatral: } \\
\text { J.M.Cano 17/1/59 } \\
\text { "vulgar" } \\
\text { "turbia" } \\
\text { "Familia amoral y } \\
\text { desunida" } \\
\text { M. Villares } \\
\text { 12/1/59 } \\
\text { p.31 II, No para } \\
\text { menores } \\
\text { "desentona" } \\
\text { G. Montes Agudo } \\
\text { 28/1/59 } \\
\text { Pamela, excesos } \\
\text { verbales } \\
\text { Sección ratifica } \\
\text { autorización y } \\
\text { supresiones } 2 / 2 / 59\end{array}$ & $\begin{array}{l}\text { G2, Supresiones } \\
\text { en pp. 19, 53, 60, } \\
75,87 \\
\text { (libreto Escelicer, } \\
78782 \text { ) } \\
\\
\text { G3 } \\
\text { Supresiones en } \\
\text { pp. } 19,53,60 \text {, } \\
75,87\end{array}$ \\
\hline $\begin{array}{l}62 / 64 \\
\text { El oído } \\
\text { privado, El } \\
\text { ojo público }\end{array}$ & $\begin{array}{l}\text { Solicitud 18/3/64 } \\
\text { Resolución } \\
25 / 3 / 64\end{array}$ & $\begin{array}{l}\text { González Vergel } \\
\text { Miguel Rubio } \\
\text { Compañía Lina Rosales }\end{array}$ & $\begin{array}{l}\text { Autorizada } \\
\text { G1 25/3/64 } \\
\text { Teatro Club } \\
\text { Madrid }\end{array}$ & $\begin{array}{l}\text { Artola } \\
\text { Mostaza } \\
\text { Arroitia }\end{array}$ & $\begin{array}{l}\text { G1 supresiones II } \\
11,50 \\
\text { "Los hombres ne- } \\
\text { cesitan ser infieles". }\end{array}$ \\
\hline $\begin{array}{l}\text { 362/67 } \\
\text { El Apagón }\end{array}$ & $\begin{array}{l}\text { Solicitud } \\
\text { 29/11/67 } \\
\text { Resolución } \\
7 / 12 / 67\end{array}$ & $\begin{array}{l}\text { Vicente Balart traductor } \\
\text { Compañía Juanjo } \\
\text { Menéndez } \\
\text { Teatro Eslava }\end{array}$ & $\begin{array}{l}\text { Autorizada } \\
\text { G1 } 7 / 12 / 67 \\
\text { Visado ensayo } \\
\text { general }\end{array}$ & $\begin{array}{l}\text { Artola } \\
\text { Barceló } \\
\text { Sunyer }\end{array}$ & $\begin{array}{l}\text { G1 Supresiones I, } \\
\text { pp. } 35,57,57, \text { II, } \\
\text { pp. } 3,8,27 \\
\text { "homosexualidad" } \\
\text { ("ejército") }\end{array}$ \\
\hline $\begin{array}{l}324 / 74 \\
\text { Equus } \\
237 / 83 \\
\text { Equus }\end{array}$ & 1974 & $\begin{array}{l}\text { Libreto (AGA } 85564, \\
85556) \\
\begin{array}{l}24 / 5 / 83 \\
\text { "La Troya", Villarrobledo }\end{array}\end{array}$ & $\begin{array}{l}\text { Calificación } \\
\text { Mayores de } 16 \\
\text { Por mayoría } \\
\text { Ordenación, } \\
\text { R.D. 262/78 }\end{array}$ & & \\
\hline $\begin{array}{l}3 / 69 \\
\text { La caza } \\
\text { real del sol }\end{array}$ & $\begin{array}{l}\text { Solicitud } \\
\text { 2/5/1974 } \\
\text { Guía } 1 \\
\text { 14/5/1974 }\end{array}$ & $\begin{array}{l}\text { Manuel Collado } \\
\text { V. Balart } \\
\text { Director: } \\
\text { A. Marsillach Teatro } \\
\text { Beatriz }\end{array}$ & $\begin{array}{l}\text { Prohibida } \\
\text { Pleno Junta de } \\
\text { Censura } \\
\text { Autorizada } \\
\text { G1 } \\
\text { Mayores de } 18 \\
\text { Sin cortes }\end{array}$ & $\begin{array}{l}3 \text { censores } \\
\text { Cea }(\mathrm{P}) \\
\text { Bautista de la } \\
\text { Torre (P) } \\
\text { Muelas (A) } \\
2 \text { lecturas más } \\
\text { Barceló (M18) } \\
\text { Mampaso (P) } \\
\text { Pleno }\end{array}$ & \\
\hline
\end{tabular}


Material Gráfico:

EXPEDIENTES DE CENSURA CONSULTADOS EN AGA Y PRENSA

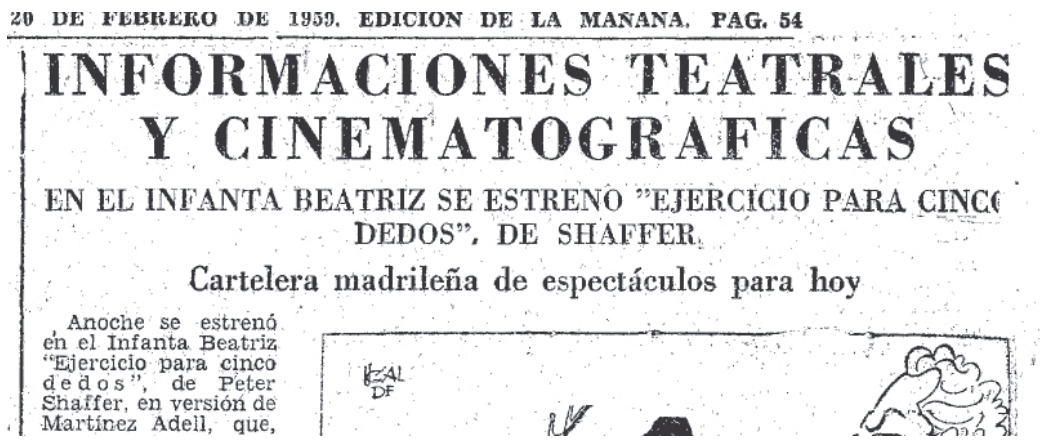

Ejercicio para cinco dedos: $A B C, 20 / 2 / 1959$

EN HONOR DE PETER SHAFFER

El próximo domingo, día 12 , se celebrará en el Inf́anta Beatriz un homenaje en honor del autor de "Ejercicio para cinzo dedos", Peter shaffer. La representación extraordinaria de dicha obra estará.pátrocinada por el Instituto Sritánico. Don Nicolás González Ruiz, en nombre de la Asociación de la Crítica, y $D$. Antonio Euero tallejo, por los autores españoles, ofrecerán el agasajo a. Shaffer, que asistirá personalmente a la función.

Homenaje a Peter Shaffer: $A B C, 9 / 4 / 1959$

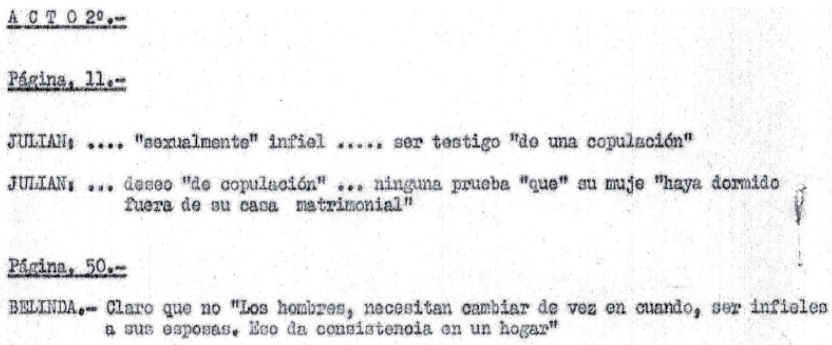

Expediente 62/64 El oído privado, El ojo público: cortes propuestos 


\section{TEATRO CLOB: "EL CEDO PEI- VADO" Y "EL OJO PUELICO"}

Autor: Peter Shaffer. Versión española: Miguel Rubio. Director: Alberto González Vergel. Intérpretes: Lina Rosales, Andrés Mejuto, Pastor Serrador, Di onisio Salamanca $\boldsymbol{y}$ Francisco Valladares.

.on dos ensayos. O dos cuentos dramáticamente desarrollados. O dos ejercicios del autor para hacer dedos. O dos "divertimentos". En cualquiera de estos marcos podemos encerrar "El oido privado" $y$ " $E l$ ojo público", las dos obritas de Peter Shaffer que en momentos parecen ensayos, en otros, cuentos, o divertimentos, o trabajos de laboratorio. No sé el tiempo que

Estreno El oido privado, El ojo público: $A B C, 31 / 3 / 1964$

\section{DORSO QUE SE CITA}

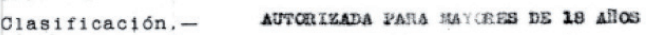

* Radiable.- $\quad$ so

Costes:- CORTE PRIMBRO

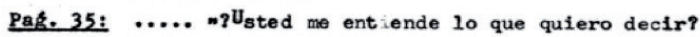

Pag. 36: …. mAprovechate ahora"

Pag. 37: …… (HAROLD le coge una mano, BRIN se suelta con un breve monotazo y se rle nerviosamente)

Bag. 42 ..... mPero ahora comprendo que he sido uno de tantos"

Pág. 50 ..... michelangelo alimentaba pasiones de naturaleza muy dis-t1ntaw

Pég. 51

ACTO SEGUNDO

CAROL.- =?Esta seguro, señor Gerringe?. No lo sabla.

Ṕgg. 3.- HAROLD.- ... "?Ahora? ?Te parece el momento adecuado?"

Pagina 8: CLBA.- .... "'sa toma de contacto nos relajará a los dos"

Pág. 27:

...... -Yo no sé que le pasa a esta nuria, que todas las veces que sale con un muchacho regresa a casa con dolor de tripas"....

AL VISAR EL ENSAYO GENERAL, se cuidar especialmente la realización de las escenas de la pág. 56 del acto primero, y 1 y 15 del acto segundo, $y$ se evitar asimismo que en la interpreta-c1ón y realización de la obra se produecan situaciones o ins1nuaciones equifrocas de carácter homoxesual.

Adaptaciones.-

Expediente 362/67 El apagón: cortes propuestos 


\section{INFORME DE LA SECCION DE LICENCIAS E INSPECCION}

La Junta de Censura Teatral, en su sesión del día 16 del mes de enero según acta que se acompaña, ha dictaminado la obra original de Peter Shaffer , versión española de Vicente Balart , titulada "LiL APAGOZ"

aprobando su representación bajo las siguientes normas complementarias:

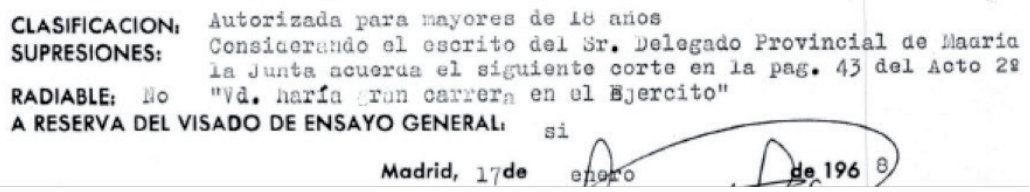

Expediente 362/67 El apagón: corte propuesto, tras visado de ensayo general

OBRA TITULADA; "LA CAZA REAL DEL SOL"

AUTOR : PITER SHAFPER

TRADUCTOR; Vicente Balart

VOCALES QUE AUTORIZAN ESTA OBRA PARA HAYORES DE 18 ANOOS SIIN CORTES:

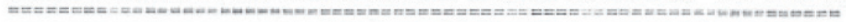

SR. BARCEt,O, SR. DIBZ CRESPO, SR, MUELAS

VOCAJES QUE AUTORIZAN ESTA OBRA PARA WAYODES DE 18 ANOS CON CORTES:

SR, ARAGONES, SRTA. MORALES, SRTA. SUMYER, SR. PARDO

VOCAL QUE AUTORIZA PARA CAILARA SIN SUPRESIONES

RVD. P. ARTOLA

TORAL DE VOCATES QUE LA AUTORTZAN:

VOCALES QUE PROHIBEN ESTA OBRA:

RVD. P. CEA, SR. B. DE LA TORRE, SR. BLORRIAGA, SR. MAIPASO, SR. WARTTHEZ RUIZ, SR. TRJ ZDOR, SR. SORIA, SR. VAZQUEZ DODFRO, SR. SUEVOS, SR. PRAGA, SR. ORTIZ $46 \% \frac{7}{3}$

TOTAL DE VOCALES QUE LA PROHIBRN: 1 Y

Expediente 3/69 La caza real del sol: resolución final, pleno de la junta 


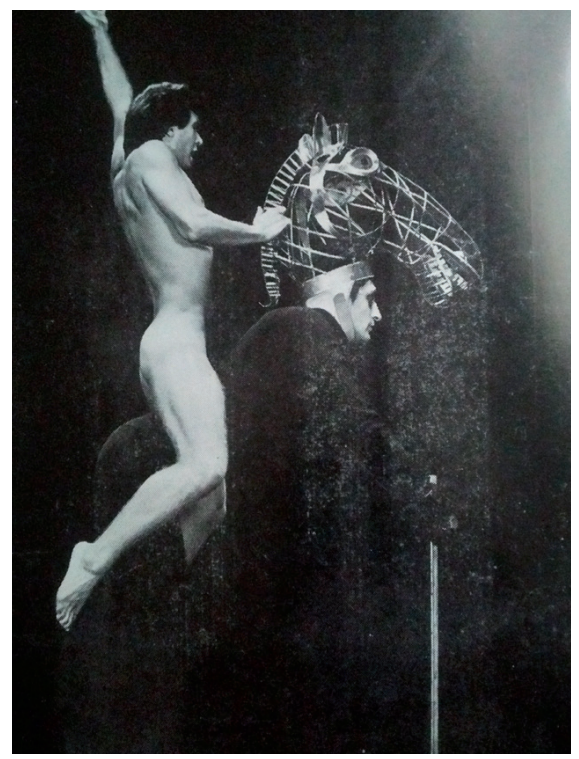

Estreno Equus: Francisco Álvaro 1975

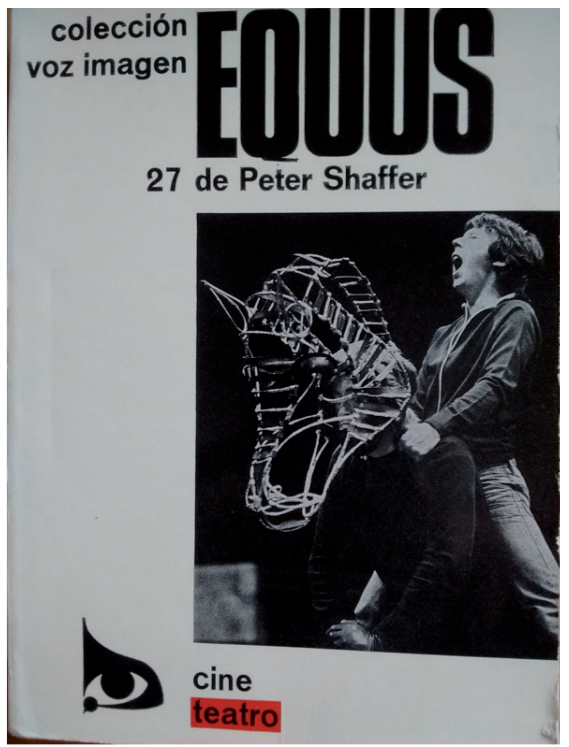

Publicación Equus: Aymà 1979 


\section{Corpus ShafferES}

ShafferES_Ejercicio: Fragmentos textuales tachados EN El EXPEDIENTE DE CENSURA

\begin{tabular}{|c|c|c|}
\hline Original inglés & Traducción mecanografiada & Traducción publicada en Escelicer \\
\hline WALTER: Where does she live? & WALTER: ¿Dónde vive? & WALTER: ¿Dónde vive? \\
\hline $\begin{array}{l}\text { PAMELA: Over the stables in } \\
\text { Craven Lane. You'll just fall when } \\
\text { you see her. }\end{array}$ & $\begin{array}{l}\text { PAMELA: Junto a las caballeri- } \\
\text { zas. En cuanto la conozca, enlo- } \\
\text { quecerá usted. }\end{array}$ & $\begin{array}{l}\text { PAMELA: Junto a las caballeri- } \\
\text { zas. En cuanto la conozca, enlo- } \\
\text { quecerá usted. }\end{array}$ \\
\hline $\begin{array}{l}\text { WALTER: How? In love? [He } \\
\text { puts on his spectacles] }\end{array}$ & WALTER: ¿De qué? ¿De amor? & $\begin{array}{l}\text { WALTER: [Sonrie] ¿De qué? ¿De } \\
\text { amor? }\end{array}$ \\
\hline $\begin{array}{l}\text { PAMELA: Of course. Mummy } \\
\text { says she's common, but that's } \\
\text { just because she wears shocking } \\
\text { pink socks and says, "Drop dead" } \\
\text { all the time. I know her mother } \\
\text { drinks and has lovers and things. } \\
\text { But her husband's dead so you re- } \\
\text { ally can't blame her, can you? Just } \\
\text { like Clive says: there-but-for-the- } \\
\text { grace-of-God department. }\end{array}$ & $\begin{array}{l}\text { PAMELA: Naturalmente. Mamá } \\
\text { dice que es una ordinaria, porque } \\
\text { lleva unas medias rosa de lo más } \\
\text { llamativo y dice O.K. a cada mo- } \\
\text { mento. Me he enterado de que } \\
\text { su madre bebe y tiene amantes } \\
\text { y demás. Pero comoes viucta no } \\
\text { se le puede censurar, ¿verdad? } \\
\text { [TACH] }\end{array}$ & $\begin{array}{l}\text { PAMELA: Naturalmente. Mamá } \\
\text { dice que es una ordinaria, porque } \\
\text { lleva unas medias rosas de lo más } \\
\text { llamativo y dice O.K. a cada mo- } \\
\text { mento. Me he enterado de que } \\
\text { su madre bebe y tiene amantes y } \\
\text { demás. Pero como es viuda no se } \\
\text { le puede censurar, ¿verdad? }\end{array}$ \\
\hline $\begin{array}{l}\text { WALTER: And she knows all } \\
\text { about America because she says, } \\
\text { "Drop dead"? }\end{array}$ & $\begin{array}{l}\text { WALTER: ¿Y por qué sabe tantas } \\
\text { cosas sobre América? ¿Nada más } \\
\text { que porque dice O.K.? }\end{array}$ & $\begin{array}{l}\text { WALTER: ¿Y por qué sabe tantas } \\
\text { cosas sobre América? ¿Nada más } \\
\text { que porque dice O.K.? }\end{array}$ \\
\hline
\end{tabular}




\begin{tabular}{|c|c|c|}
\hline Original inglés & Traducción mecanografiada & Traducción publicada en Escelicer \\
\hline $\begin{array}{l}\text { STANLEY: [seizing Clive; } \\
\text { relentlessly] Tell me what } \\
\text { happened with Walter? }\end{array}$ & $\begin{array}{l}\text { STANLEY: [Implacable] ¿Qué ha } \\
\text { pasado con Walter? ¡Contéstame! }\end{array}$ & $\begin{array}{l}\text { STANLEY: [Implacable] ¿Qué ha } \\
\text { pasado con Walter? ¡Contéstame! }\end{array}$ \\
\hline $\begin{array}{l}\text { [They struggle together, then Clive } \\
\text { disengages himself, pushes Stanley } \\
\text { to L and rushes to the hall door. } \\
\text { Stanley tosses the spectacles on to the } \\
\text { seat of the armchair. Clive pauses at } \\
\text { the door, then suddenly closes it and } \\
\text { moves down L of the sofa] }\end{array}$ & $\begin{array}{l}\text { [Clive corre hacia la puerta. } \\
\text { Entonces súbitamente cambia de } \\
\text { pensamiento, la cierra, se vuelve y } \\
\text { se enfrenta con su padre] }\end{array}$ & $\begin{array}{l}\text { [Clive corre hacia la puerta. } \\
\text { Entonces, súbitamente cambia de } \\
\text { pensamiento, la cierra, se vuelve y } \\
\text { se enfrenta con su padre] }\end{array}$ \\
\hline $\begin{array}{l}\text { CLIVE: [after a pause] It was } \\
\text { mother. }\end{array}$ & $\begin{array}{l}\text { CLIVE: [Lentamente] Estaba con } \\
\text { mamá. }\end{array}$ & $\begin{array}{l}\text { CLIVE: [Lentamente] Estaba con } \\
\text { mamá. }\end{array}$ \\
\hline $\begin{array}{l}\text { STANLEY: [moving up } R \text { of the } \\
\text { armchair] What? }\end{array}$ & STANLEY: ¿Qué? & STANLEY: ¿Qué? \\
\hline $\begin{array}{l}\text { CLIVE: There on the sofa. I saw } \\
\text { them. I came in and there they } \\
\text { were. [He turns to face Stanley } \\
\text { and stands close by the sofa] The } \\
\text { light was turned down. They } \\
\text { were kissing. Kissing. She was } \\
\text { half undressed. And he was } \\
\text { kissing her, on the mouth. On } \\
\text { the breasts. Kissing... [Stanley } \\
\text { raises his arm as though to hit } \\
\text { Clive who sinks on to the sofa, } \\
\text { facing Stanley] [Hard] And before } \\
\text { that, I think the light had been } \\
\text { turned off. [Stanley stares at Clive, } \\
\text { stunned] [He looks up at Stanley] } \\
\text { Department of Just Deserts? }\end{array}$ & $\begin{array}{l}\text { CLIVE: ¡Ahí, en el sofá! Les vi. } \\
\text { Entré de repente y los sorprendí. } \\
\text { Las luces estaban apagadas. Y se } \\
\text { estaban besando. ¡Besándose! } \\
\text { Ella estaba medio desnuda y } \\
\text { ét la estaba besando. [TACH] } \\
\text { Besando en la boca. ¡Besándola! } \\
\text { [Stanley le da un bofetón. Clive } \\
\text { cae sobre el sofá llorando, mientras } \\
\text { repite] ¡Besándola! ¡Besándola! } \\
\text { ¡Besándola! [Stanley se le queda } \\
\text { mirando, atónito. Las gafas se le } \\
\text { caen de la mano, sobre el sillón] }\end{array}$ & $\begin{array}{l}\text { CLIVE: ¡Ahí, en el sofá! Los vi. } \\
\text { Entré de repente y los sorprendí. } \\
\text { Las luces estaban apagadas. Y se } \\
\text { estaban besando. ¡Besándose! } \\
\text { Ella estaba medio desnuda y él } \\
\text { la estaba besando. Besando en } \\
\text { la boca. ¡Besándola! [Stanley le } \\
\text { da un bofetón. Clive cae sobre } \\
\text { el sofá llorando, mientras repite] } \\
\text { ¡Besándola!... ¡Besándola! } \\
\text { ¡Besándola! [Stanley se le queda } \\
\text { mirando, atónito. Las gafas se le } \\
\text { caen de la mano, sobre el sillón] }\end{array}$ \\
\hline [CURTAIN] & [TELÓN] & [TELÓN] \\
\hline
\end{tabular}




\begin{tabular}{|c|c|c|}
\hline Original inglés & Traducción mecanografiada & Traducción publicada en Escelicer \\
\hline $\begin{array}{l}\text { CLIVE: [bowing in Oriental } \\
\text { fashion to Pamela] Good morning. }\end{array}$ & $\begin{array}{l}\text { CLIVE: [Bostezando] Buenos } \\
\text { días. }\end{array}$ & CLIVE: Buenos días. \\
\hline & & WALTER: Buenos días. \\
\hline $\begin{array}{l}\text { PAMELA: [bowing; in the act } \\
\text { at once] Salaams. A thousand } \\
\text { welcomes, O handsome slave } \\
\text { boy, mine eyes rejoice in the sight } \\
\text { of you. [She moves to Clive, seizes } \\
\text { him and swings him round] Dance } \\
\text { for me, my little pomegranate. } \\
\text { Madden me with desire. }\end{array}$ & $\begin{array}{l}\text { PAMELA: [Le hace una reverencia } \\
\text { oriental] ¡Alá te guarde! ¡Oh, } \\
\text { bellísimo esclavo, mis ojos se } \\
\text { complacen en tu vista! ¡Danza } \\
\text { para mí, esclavo mío! ¡Hazme } \\
\text { arderendeseo! [TACH] }\end{array}$ & $\begin{array}{l}\text { PAMELA: [Le hace una reverencia } \\
\text { oriental] ¡Alá te guarde! ¡Oh, } \\
\text { bellísimo esclavo, mis ojos se } \\
\text { complacen en tu vista! ¡Danza } \\
\text { para mí, esclavo mío! ¡Hazme } \\
\text { arder en deseo! }\end{array}$ \\
\hline $\begin{array}{l}\text { CLIVE: Drop dead! [He goes } \\
\text { down the schoolroom stairs, sees } \\
\text { Walter, pauses and stares at him for } \\
\text { a moment] Good morning. }\end{array}$ & $\begin{array}{l}\text { CLIVE: ¡Anda y muérete! }[A \\
\text { Walter] Buenos días. }\end{array}$ & CLIVE: ¡Anda y muérete! \\
\hline
\end{tabular}

\begin{tabular}{|c|c|c|}
\hline Original inglés & Traducción mecanografiada & Traducción publicada en Escelicer \\
\hline $\begin{array}{l}\text { WALTER: [putting on his } \\
\text { spectacles] She is worried about } \\
\text { Clive. }\end{array}$ & $\begin{array}{l}\text { WALTER: Está preocupada por } \\
\text { Clive. }\end{array}$ & $\begin{array}{l}\text { WALTER: Está preocupada por } \\
\text { Clive. }\end{array}$ \\
\hline $\begin{array}{l}\text { PAMELA: [leaning over the back of } \\
\text { her chair] Phooey! Anyone would } \\
\text { think he was still a baby, the way } \\
\text { she goes on. [She straightens up. } \\
\text { Wickedly] I hope he stays out all } \\
\text { night. Wouldn't it be wonderful } \\
\text { if he was giving babies to all the } \\
\text { schoolgirls in Ipswich? [In an } \\
\text { affected voice] Well, I'd better go } \\
\text { and have a bath, dear boy. [Pamela } \\
\text { exits to her bedroom. Louise enters by } \\
\text { the front door, goes into the living- } \\
\text { room, switches on the lights R, crosses } \\
\text { and exits by the french windows, } \\
\text { leaving the windows open. Pamela } \\
\text { enters from her bedroom carrying } \\
\text { her dressing-gown, nightdress and } \\
\text { slippers] Oh, Lord, Sunday night. } \\
\text { Breakfast at half past seven for that } \\
\text { rotten train. [She goes down the } \\
\text { schoolroom stairs] I think Mondays } \\
\text { stink. [She runs back up the stairs to } \\
\text { the schoolroom] Is there any religion } \\
\text { with its Day of Rest on Mondays? }\end{array}$ & $\begin{array}{l}\text { PAMELA: ¡Bah! Cualquiera } \\
\text { diría que es todavía un niño, por } \\
\text { la forma en que lo trata. [Con } \\
\text { perversidad cómica] Espero que } \\
\text { no aparezca hasta mañana. Quué } \\
\text { estupendo serría que tes hiciera unr } \\
\text { niño a todas las chieas de Ipswieh! } \\
\text { [TACH] [Entra en su cuarto desde } \\
\text { donde habla. Voz afectada] Bueno, } \\
\text { lo más prudente es que me vaya } \\
\text { al baño. ¡Dios mío, noche de } \\
\text { domingo! Mañana desayuno } \\
\text { a las siete y media para coger el } \\
\text { maldito tren. Yo creo que el lunes } \\
\text { es el día más horroroso... [Vuelve } \\
\text { envuelta en el albornoz] ¿Hay } \\
\text { alguna religión que tenga el lunes } \\
\text { por día de descanso? }\end{array}$ & $\begin{array}{l}\text { PAMELA: ¡Bah! Cualquiera } \\
\text { diría que es todavía un niño, por } \\
\text { la forma en que lo trata. [Con } \\
\text { perversidad cómica] Espero que } \\
\text { no aparezca hasta mañana. ¡Qué } \\
\text { estupendo sería que les hiciese un } \\
\text { niño a todas las chicas de Ipswich! } \\
\text { [Entra en su cuarto desde donde } \\
\text { habla. Voz afectada] Bueno, lo } \\
\text { más prudente es que vaya al bańo. } \\
\text { ¡Dios mío, noche de domingo! } \\
\text { Mañana desayuno a las siete y } \\
\text { media para coger el maldito tren. } \\
\text { Yo creo que el lunes es el día más } \\
\text { horroroso... [Vuelve envuelta en } \\
\text { el albornoz] ¿Hay alguna religión } \\
\text { que tenga el lunes por día de } \\
\text { descanso? }\end{array}$ \\
\hline $\begin{array}{l}\text { WALTER: Yes, the religion of } \\
\text { Lazy Girls. }\end{array}$ & $\begin{array}{l}\text { WALTER: Sí. La religión de los } \\
\text { vagos. }\end{array}$ & $\begin{array}{l}\text { WALTER: Sí. La religión de los } \\
\text { vagos. }\end{array}$ \\
\hline
\end{tabular}




\begin{tabular}{|l|l|l|}
\hline Original inglés & Traducción mecanografiada & Traducción publicada en Escelicer \\
\hline $\begin{array}{l}\text { WALTER: You forget—you } \\
\text { asked me for my opinion. }\end{array}$ & $\begin{array}{l}\text { WALTER: Se olvida de que fue } \\
\text { usted el que preguntó mi opinión. }\end{array}$ & $\begin{array}{l}\text { WALTER: Se olvida de que fue } \\
\text { usted el que preguntó mi opinión. }\end{array}$ \\
\hline $\begin{array}{l}\text { STANLEY: Oh, yes. And what } \\
\text { else did I ask you to do? [He moves } \\
\text { to L of Walter] Turn my son into } \\
\text { a cissy? }\end{array}$ & $\begin{array}{l}\text { STANLEY: ¿Y qué más? ¿Le pedí } \\
\text { también que convirtiese a mi hijo } \\
\text { enunmariea? [TACH] }\end{array}$ & $\begin{array}{l}\text { STANLEY: ¿Y qué más? ¿Le pedí } \\
\text { también que convirtiese a mi hijo } \\
\text { en un marica? }\end{array}$ \\
\hline $\begin{array}{l}\text { WALTER: [retreating below the } \\
\text { armchair] Your son is a fine, } \\
\text { intelligent boy. }\end{array}$ & $\begin{array}{l}\text { WALTER: Su hijo es un un } \\
\text { muchacho bueno e inteligente. }\end{array}$ & $\begin{array}{l}\text { WALTER: Su hijo es un } \\
\text { muchacho bueno e inteligente. }\end{array}$ \\
\hline
\end{tabular}

\section{ShafferES_CAZA: Posibles vestigios de Autocensura}

\begin{tabular}{|l|l|}
\hline Original inglés & Traducción mecanografiada \\
\hline [Darkness. OLD MARTIN, grizzled, in his middle & [Aparece el viejo Martin.] \\
fifties, appears. He wears the black costume of a Spanish \\
hidalgo in the mid sixteenth century.]
\end{tabular}




\section{"Peru, the land I helped ruin as a boy" ('Perú, el país que ayudé a destruir cuando era joven') se traduce como "Perú, esa tierra que pisé por primera vez hace luengos años siendo un mozalbete".}

\begin{tabular}{|l|l|}
\hline Original inglés & Traducción mecanografiada \\
\hline $\begin{array}{l}\text { ATAHUALLPA: They will never move from there. At birth of a son } \\
\text { one more tupu will be given. At birth of a daughter, half a tupu. } \\
\text { At fifty all people will leave work for ever, and be fed in honour till } \\
\text { they die. }\end{array}$ & $\begin{array}{l}\text { ATAHUALPA: Nunca se moverán de allí. Al nacimiento de un } \\
\text { hijo, se les dará un nuevo tupu. Si nace una hembra, medio tupu. } \\
\text { A los cincuenta ańos, todos dejarán de trabajar para siempre y serán } \\
\text { honrados hasta que mueran. }\end{array}$ \\
\hline $\begin{array}{l}\text { DE SOTO: I have settled several lands. This is the first I've entered } \\
\text { which shames our Spain. }\end{array}$ & $\begin{array}{l}\text { PIZARRO: Por mi vida que he pisado muchos países y éste es el } \\
\text { primero en que hallo un entendimiento cabal de lo que debe ser el } \\
\text { gobierno de una nación... }\end{array}$ \\
\hline $\begin{array}{l}\text { ESTETE: Shames? } \\
\begin{array}{l}\text { PIZARRO: Oh, it's not difficult to shame Spain. Here shames every } \\
\text { country which teaches we are born greedy for possessions. Clearly } \\
\text { we're made greedy when we're assured it's natural. But there's a picture } \\
\text { for a Spanish eye! There's nothing to covet, so covetousness dies at } \\
\text { birth. }\end{array}\end{array}$ \\
\hline
\end{tabular}

"I have settled several lands. This is the first I've entered which shames our Spain" ("He visitado muchos países y este es el primero que deja en evidencia a España') se traduce como "Por mi vida que he pisado muchos países y éste es el primero en que hallo un entendimiento cabal de lo que debe ser el gobierno de una nación”. Se suprimen las dos siguientes réplicas.

\begin{tabular}{|c|c|}
\hline Original inglés & Traducción mecanografiada \\
\hline $\begin{array}{l}\text { VALVERDE: My son, listen to me. No promise to } \\
\text { a pagan need bind a Christian. Simply think what's } \\
\text { at stake: the lives of a hundred and seventy of the } \\
\text { faithful. Are you going to sacrifice them for one } \\
\text { savage? }\end{array}$ & $\begin{array}{l}\text { FRAY VALVERDE: Escuchadme, hijo mío. } \\
\text { Ninguna promesa hecha a un pagano puede retener } \\
\text { a un cristiano. Pensad únicamente en el riesgo que } \\
\text { corren las vidas de ciento setenta fieles. ¿Vais a } \\
\text { sacrificarles a todos por un salvaje perverso y malo? } \\
\text { Porque ese hombre lleva el demonio dentro de sí. Su } \\
\text { pueblo besa sus manos como la fuente de la vida. }\end{array}$ \\
\hline \multicolumn{2}{|l|}{$\begin{array}{l}\text { PIZARRO: You know lives have no weight, Father. } \\
\text { Ten can't be added up to outbalance one. }\end{array}$} \\
\hline \multicolumn{2}{|l|}{$\begin{array}{l}\text { VALVERDE: Ten good can against one evil. And } \\
\text { this man is evil. His people kiss his hands as the } \\
\text { source of life. }\end{array}$} \\
\hline $\begin{array}{l}\text { PIZARRO: As we do yours. All your days you play } \\
\text { at being God. You only hate my Inca because he } \\
\text { does it better. }\end{array}$ & $\begin{array}{l}\text { PIZARRO: Igual que nosotros besamos las vuestras. } \\
\text { Son dos religiones enfrentadas. Si Cristo estuviese } \\
\text { aquí ahora ¿creéis que mataría a mi Inca? Vos, Fray } \\
\text { Marcos, que tenéis respuesta para todo, decidme: } \\
\text { ¿Lo mato? }\end{array}$ \\
\hline VALVERDE: What? & \\
\hline
\end{tabular}




\begin{tabular}{|c|c|}
\hline $\begin{array}{l}\text { PIZARRO: Dungballs to all churches that are } \\
\text { or ever could be! How I hate you. 'Kill who I bid } \\
\text { you kill and I will pardon it!' You with your milky } \\
\text { fingers forcing in the blade! How dare you priests } \\
\text { bless any man who goes slicing into battle? But no: } \\
\text { you slice with him! 'Rip!' you scream, 'tear! blind! in } \\
\text { the name of Christ!' ... Tell me, soft Father, if Christ } \\
\text { was here now, do you think he would kill my Inca? } \\
\text { [Pause.] Well, Brother de Nizza, you're the lord of } \\
\text { answers: let's hear you. Do I kill him? }\end{array}$ & \\
\hline $\begin{array}{l}\text { DE NIZZA: Don't try and trap me. I know as well } \\
\text { as you how terrible it is to kill. But worse is to spare } \\
\text { evil. When I came here first I thought I had found } \\
\text { Paradise. Now I know it is Hell. A country which } \\
\text { castrates its people. What are your Inca's subjects? } \\
\text { A population of eunuchs, living entirely without } \\
\text { choice. }\end{array}$ & $\begin{array}{l}\text { FRAY MARCOS: No tratéis de atraparme. Yo sé } \\
\text { bien cuan terrible es matar. Pero peor es abstenerse } \\
\text { en ocasiones. Porque ¿qué son los súbditos de } \\
\text { vuestro Inca? Una población de eunucos, que viven } \\
\text { sin posibilidad de escoger. }\end{array}$ \\
\hline $\begin{array}{l}\text { PIZARRO: And what are your Christians? Unhappy } \\
\text { hating men. Look: I'm a peasant, I want value for } \\
\text { money. If I go marketing for gods, who do I buy? } \\
\text { The God of Europe with all its death and blooding, } \\
\text { or Atahuallpa of Peru? His spirit keeps an empire } \\
\text { sweet and still as com in the field. }\end{array}$ & $\begin{array}{l}\text { PIZARRO: ¿Y qué son los cristianos? Hombres } \\
\text { infelices y hambrientos. España está habitada por } \\
\text { masas de vagabundos, de gente que padece hambre, } \\
\text { en tanto que una exigua minoría disfrutan y se } \\
\text { reparten las restas del país. ¿Es justo esto? Decidme, } \\
\text { jes justo que suceda tal cosa? Estos hombres del Sol } \\
\text { no son estúpidos. Saben que venimos a venderles } \\
\text { hambre únicamente. Ellos viven aquí como una } \\
\text { parte de la naturaleza. Las sabias leyes del Inca } \\
\text { mantienen un imperio pacífico, floreciente y los } \\
\text { campos con trigo abundante. }\end{array}$ \\
\hline
\end{tabular}

Se elimina "All your days you play at being God. You only hate my Inca because he does it better" ('Todos los días juegas a ser Dios. Odias al Inca solo porque él lo hace mejor'), "Dungballs to all churches that are or ever could be! How I hate you. "Kill who I bid you kill and I will pardon it!». You with your milky fingers forcing in the blade! How dare you priests bless any man who goes slicing into battle? But no: you slice with him!

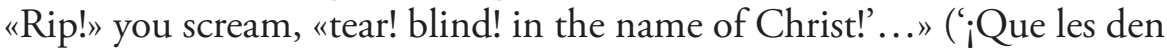
a todas las iglesias que hay y que pueda haber! ¡Cómo os odio! “¡Mata a quien te ordeno que mates y te perdonaré!” ¡Vosotros con vuestros dedos blanquecinos empunáis la espada! ¿Cómo os atrevéis los curas a bendecir a un hombre que mata en batallas? ¡Pero no, matáis con él! Gritáis: “¡Desgarra! ¡Rompe! ¡Ciega! ¡En nombre de Cristo!...’) y “If I go marketing for gods, who do I buy?” ('Si voy a comprar un dios, ¿con cuál me quedo?’). 


\begin{tabular}{|c|c|}
\hline Original inglés & Traducción mecanografiada \\
\hline $\begin{array}{l}\text { ESTETE: You madman: see here, you put him } \\
\text { underground by sunset or I'll take the knife to him } \\
\text { myself. }\end{array}$ & $\begin{array}{l}\text { ESTETE: Poned un término a vuestro desvarío, } \\
\text { capitán Pizarro. Que este hombre esté bajo tierra al } \\
\text { anochecer o yo mismo acabaré con él. }\end{array}$ \\
\hline $\begin{array}{l}\text { PIZARRO: ATAHUALLPA! [Atahuallpa enters } \\
\text { with Young Martin.] They ache for your death. They } \\
\text { want to write psalms to their god in your blood. But } \\
\text { they'll all die before you - that I promise. [He binds } \\
\text { Atahuallpa's arm to his own with a long cord of rope } \\
\text { last used to tie some gold.] There. No, no, some here. } \\
\text { Now no one will kill you unless they kill me first. }\end{array}$ & $\begin{array}{l}\text { PIZARRO: iATAHUALPA! [Entra Atabualpa con el } \\
\text { joven Martín.] Mi gente exige tu cabeza. Pero como } \\
\text { me llamo Pizarro que nadie ha de tocarte mientras } \\
\text { me quede un soplo de vida. [Ata un brazo del inca } \\
\text { al suyo con un largo cabo de soga.] Un solo cuerpo, } \\
\text { una sola atadura. Así, para matarte, tendrán que } \\
\text { matarme a mi primero. }\end{array}$ \\
\hline
\end{tabular}

\section{Se elimina "They want to write psalms to their god in your blood" ('Quie- ren escribir salmos a su dios con tu sangre').}

\begin{tabular}{|c|c|}
\hline Original inglés & Traducción mecanografiada \\
\hline $\begin{array}{l}\text { PIZARRO: Cheat! You've cheated me! Cheat... } \\
\text { [For a moment his old body is racked with sobs; then, } \\
\text { surprised, he feels tears on his cheek. He examines them. } \\
\text { The sunlight brightens on his head.] What's this? What } \\
\text { is it? In all your life you never made one of these, } \\
\text { I know, and I not till this minute. Look. [He kneels } \\
\text { to show the dead Inca.] Ah, no. You have no eyes for } \\
\text { me now, Atahuallpa: they are dusty balls of amber I } \\
\text { can tap on. You have no peace for me, Atahuallpa: } \\
\text { the birds still scream in your forest. You have no joy } \\
\text { for me, Atahuallpa, my boy: the only joy is in death. } \\
\text { I lived between two hates: I die between two darks: } \\
\text { blind eyes and a blind sky. And yet you saw once. } \\
\text { The sky sees nothing, but you saw. Is there comfort } \\
\text { there? The sky knows no feelings, but we know them, } \\
\text { that's sure. Martin's hope, and De Soto's honour, and } \\
\text { your trust - your trust which hunted me: we alone } \\
\text { make these. That's some marvel, yes, some marvel. } \\
\text { To sit in a great cold silence, and sing out sweet with } \\
\text { just our own warm breath: that's some marvel, surely. } \\
\text { To make water in a sand world: surely, surely... God's } \\
\text { just a name on your nail; and naming begins cries and } \\
\text { cruelties. But to live without hope of after, and make } \\
\text { whatever God there is, oh, that's some immortal } \\
\text { business surely!... I'm tired. Where are you? You're so } \\
\text { cold. I'd warm you if I could. But there's no warming } \\
\text { now, not ever now. I'm colding too. There's a snow } \\
\text { of death falling all round us. You can almost see it. } \\
\text { It's over, lad, I'm coming after you. There's nothing } \\
\text { but peace to come. We'll be put into the same earth, } \\
\text { father and son in our own land. And that sun will } \\
\text { roam uncaught over his empty pasture. }\end{array}$ & $\begin{array}{l}\text { PIZARRO: ¡Me has engañado! ¡Me has engañado! } \\
\text { ¡Atahualpa! [Una sacudida de dolor recorre el cuerpo } \\
\text { del anciano capitán. Se sorprende al notar sus mejillas } \\
\text { húmedas de llanto.] ¿Qué es esto? Nunca me había } \\
\text { sucedido una cosa igual... Fíjate, estoy derramando } \\
\text { lágrimas por ti. Mis primeras lágrimas... [Se } \\
\text { arrodilla para mostrárselas al Inca muerto.] Pero tú } \\
\text { ya no tienes ojos con que mirarme, Atahualpa. Tus } \\
\text { ojos son como lejanas y oscuras bolas de ámbar... } \\
\text { Los pájaros siguen gritando en tus bosques, pero } \\
\text { tu alegría se ha ido. Atahualpa, compañero, mi } \\
\text { chiquillo. Vivía compartido por odios y tú me dejas } \\
\text { peor que viví, sumido entre dos oscuridades... } \\
\text { Dios no es más que un nombre escrito en la uña } \\
\text { de tu dedo... ¿Qué hay más allá? ¿Atahualpa? Tú } \\
\text { que ya has llegado, dímelo... Cuan frío estás... } \\
\text { te calentaría con mi aliento si pudiera... ¡Ah, que } \\
\text { cansancio!... Voy a seguir muchacho. Nos cubrirá la } \\
\text { misma tierra, como padre e hijo en nuestro propio } \\
\text { país. Y el sol, mientras vagará eternamente sobre } \\
\text { sus pastos vacíos... [Pizarro canta muy quedo.] "No } \\
\text { debes robar la cosecha de maíz pequeńo pinzón. La } \\
\text { trampa está presta para atraparte rápido pequeño } \\
\text { pinzón"... }\end{array}$ \\
\hline
\end{tabular}




\begin{tabular}{|l|l|}
\hline [Enter Old Martin.] & \\
\hline OLD MARTIN: So fell Peru. We gave her greed, & \\
hunger and the cross: three gifts for the civilized & \\
life. The family groups that sang on the terraces & \\
are gone. In their place slaves shuffle underground & \\
and they don't sing there. Peru is a silent country, & \\
frozen in avarice. So fell Spain, gorged with gold; & \\
distended; now dying. \\
\hline PIZARRO: [singing] 'Where is her heart, O little & \\
finch?'... & \\
\hline
\end{tabular}

Se elimina la réplica del viejo Martín que comienza tal que así: "So fell Peru. We gave her greed, hunger and the cross: three gifts for the civilized life" ('Y así cayó Perú. Le llevamos la avaricia, el hambre y la cruz: tres regalos para la vida civilizada').

\section{ShAFFERES_EQUUS: DIFERENCIAS ENTRE LAS TRADUCCIONES}

\begin{tabular}{|c|c|c|}
\hline Original inglés & Traducción publicada en Aymà & Traducción mecanografiada \\
\hline $\begin{array}{l}\text { DYSART: Apparently, during the } \\
\text { whole time he worked for you, he } \\
\text { never actually rode. }\end{array}$ & $\begin{array}{l}\text { DYSART: Al parecer, durante } \\
\text { todo el tiempo que trabajó para } \\
\text { usted, nunca montó a caballo. }\end{array}$ & $\begin{array}{l}\text { DYSART: ¿Y no le pareció raro } \\
\text { que solo pensara en limpiar y no } \\
\text { en montar a caballo? }\end{array}$ \\
\hline DALTON: That's true. & DALTON: Eso es cierto. & \\
\hline DYSART: Wasn't that peculiar? & DYSART: ¿No era un poco raro? & \\
\hline DALTON: Very... If he didn't. & $\begin{array}{l}\text { DALTON: Mucho... Si es que } \\
\text { nunca lo hizo. }\end{array}$ & \\
\hline $\begin{array}{l}\text { DYSART: What do you mean? } \\
\text { [DALTON rises.] }\end{array}$ & $\begin{array}{l}\text { DYSART: ¿Qué quiere usted } \\
\text { decir? [Dalton se levanta.] }\end{array}$ & \\
\hline $\begin{array}{l}\text { DALTON: Because on and off, } \\
\text { that whole year, I had the feeling } \\
\text { the horses were being taken out } \\
\text { at night. }\end{array}$ & $\begin{array}{l}\text { DALTON: Porque, de vez en } \\
\text { cuando, en el curso de ese año, } \\
\text { tuve la sensación de que alguien } \\
\text { sacaba los caballos de noche. }\end{array}$ & $\begin{array}{l}\text { DALTON: La verdad es que varias } \\
\text { veces tuve la impresión de que al- } \\
\text { guien sacaba a los caballos por la } \\
\text { noche. Había mañanas que me } \\
\text { encontraba a alguno bañado en } \\
\text { sudor y con el pesebre muy poco } \\
\text { sucio. Pero no le di importancia. } \\
\text { Es ahora cuando caigo en la cuenta } \\
\text { de que pudo montar a escondidas } \\
\text { desde la primera noche. Perdóne- } \\
\text { me doctor este asunto me tiene tan } \\
\text { trastornado, que soy capaz de ima- } \\
\text { ginar cualquier cosa. Si no necesita } \\
\text { nada más de mí, me marcho. }\end{array}$ \\
\hline
\end{tabular}




\begin{tabular}{|c|c|c|}
\hline DYSART: At night? & DYSART: ¿De noche? & \\
\hline $\begin{array}{l}\text { DALTON: There were just odd } \\
\text { things I noticed. I mean too often } \\
\text { one or other of them would be } \\
\text { sweaty first thing in the morning, } \\
\text { when it wasn't sick. Very sweaty, } \\
\text { too. And its stall wouldn't be } \\
\text { near as mucky as it should be if } \\
\text { it had been in all night. I never } \\
\text { paid it much mind at the time. It } \\
\text { was only when I realized I'd been } \\
\text { hiring a loony, I came to wonder } \\
\text { if he hadn't been riding all the } \\
\text { time, behind our backs. }\end{array}$ & $\begin{array}{l}\text { DALTON: Noté algunas cosas } \\
\text { curiosas. Me refiero a que muy } \\
\text { a menudo encontraba algún } \\
\text { animal que, a primera hora de la } \\
\text { mańana, estaba bańado en sudor, } \\
\text { a pesar de que no estaba enfermo. } \\
\text { Completamente cubierto de } \\
\text { sudor. Y su establo no estaba tan } \\
\text { sucio como debería haber estado } \\
\text { si hubiese pasado en él toda la } \\
\text { noche. En aquellos momentos } \\
\text { nunca le presté mayor atención. } \\
\text { Sólo cuando me di cuenta de que } \\
\text { había contratado a un chiflado, } \\
\text { se me ocurrió preguntarme si } \\
\text { no había estado montando los } \\
\text { caballos cuando nosotros no le } \\
\text { veíamos. }\end{array}$ & \\
\hline $\begin{array}{l}\text { DYSART: But wouldn't you } \\
\text { have noticed if things had been } \\
\text { disturbed? }\end{array}$ & $\begin{array}{l}\text { DYSART: Pero si los arreos no } \\
\text { estaban en su lugar, ¿no lo habría } \\
\text { notado? }\end{array}$ & \\
\hline $\begin{array}{l}\text { DALTON: Nothing ever was. } \\
\text { Still, he's a neat worker. That } \\
\text { wouldn't prove anything. }\end{array}$ & $\begin{array}{l}\text { DALTON: Nunca se dio el caso. } \\
\text { Además, es muy ordenado. Eso } \\
\text { nada hubiese probado. }\end{array}$ & \\
\hline $\begin{array}{l}\text { DYSART: Aren't the stables } \\
\text { locked at night? }\end{array}$ & $\begin{array}{l}\text { DYSART: ¿No cierran con llave } \\
\text { las caballerizas por la noche? }\end{array}$ & \\
\hline DALTON: Yes. & DALTON: Sí. & \\
\hline $\begin{array}{l}\text { DYSART: And someone sleeps } \\
\text { on the premises? }\end{array}$ & $\begin{array}{l}\text { DYSART: ¿Y no duerme nadie en } \\
\text { las dependencias? }\end{array}$ & \\
\hline DALTON: Me and my son. & DALTON: Yo y mi hijo. & \\
\hline DYSART: Two people? & DYSART: ¿Dos personas? & \\
\hline $\begin{array}{l}\text { DALTON: I'm sorry, Doctor. It's } \\
\text { obviously just my fancy. I tell you, } \\
\text { this thing has shaken me so bad, } \\
\text { I'm liable to believe anything. If } \\
\text { there's nothing else, I'll be going. }\end{array}$ & $\begin{array}{l}\text { DALTON: No haga caso, doctor. } \\
\text { Es evidente que se trata de una } \\
\text { fantasía mía. Todo eso me ha } \\
\text { trastornado de tal manera, que } \\
\text { soy capaz de creer cualquier cosa. } \\
\text { Si no tiene que preguntarme nada } \\
\text { más, me retiro. }\end{array}$ & \\
\hline $\begin{array}{l}\text { DYSART: Look: even if you were } \\
\text { right, why should anyone do } \\
\text { that? Why would any boy prefer } \\
\text { to ride by himself at night, when } \\
\text { he could go off with others during } \\
\text { the day? }\end{array}$ & $\begin{array}{l}\text { DYSART: Escuche: suponiendo } \\
\text { que estuviera usted en lo cierto, } \\
\text { ¿por qué tenía que hacer una } \\
\text { cosa semejante? ¿Por qué un } \\
\text { muchacho habría de preferir } \\
\text { montar a caballo de noche, solo, } \\
\text { pudiendo salir con todos los } \\
\text { demás durante el día? }\end{array}$ & $\begin{array}{l}\text { DYSART: Aunque así fuera, ¿por } \\
\text { qué iba a hacer semejante cosa? } \\
\text { ¿Qué chico preferiría montar solo } \\
\text { y por la noche, pudiendo hacerlo } \\
\text { tranquilamente durante el día? }\end{array}$ \\
\hline
\end{tabular}

